\title{
Genome-wide association study and population structure analysis of seed-bound amino acids and total protein in watermelon
}

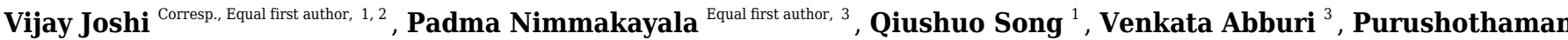 \\ Natarajan ${ }^{3}$, Amnon Levi ${ }^{4}$, Kevin Crosby ${ }^{1}$, Umesh K Reddy ${ }^{\text {Corresp. } 3}$ \\ ${ }^{1}$ Department of Horticultural Sciences, Texas A\&M University, Uvalde, Texas, United States \\ 2 Texas A\&M AgriLife Research and Extension Center, Uvalde, Texas, United States \\ 3 Department of Biology, Gus R. Douglass Institute,, West Virginia State University, Institute, Charleston, West Virginia, United States \\ ${ }^{4}$ Vegetable Laboratory,, USDA-ARS, Charleston, South Carolina, United States \\ Corresponding Authors: Vijay Joshi, Umesh K Reddy \\ Email address: vijay.joshi@tamu.edu, ureddy@wvstateu.edu
}

Background Watermelon seeds are a powerhouse of value-added traits such as proteins, free amino acids, vitamins, and essential minerals, offering a paleo-friendly dietary option. Despite the availability of substantial genetic variation, there is no sufficient information on the natural variation in seed-bound amino acids or proteins across the watermelon germplasm. This study aimed to analyze the natural variation in watermelon seed amino acids and total protein and explore underpinning genetic loci by genome-wide association study (GWAS). Methods The study evaluated the distribution of seed-bound free amino acids and total protein in 211 watermelon accessions of Citrullus spp, including 154 of Citrullus lanatus, 54 of Citrullus mucosospermus (egusi) and 3 of Citrullus amarus. We used the GWAS approach to associate seed phenotypes with 11,456 single nucleotide polymorphisms (SNPs) generated by genotyping-by-sequencing (GBS). Results Our results demonstrate a significant natural variation in different free amino acids and total protein content across accessions and geographic regions. The accessions with high protein content and proportion of essential amino acids warrant its use for value-added benefits in the food and feed industries via biofortification. The GWAS analysis identified 188 SNPs coinciding with 167 candidate genes associated with watermelon seed-bound amino acids and total protein. Clustering of SNPs associated with individual amino acids found by principal component analysis was independent of the speciation or cultivar groups and was not selected during the domestication of sweet watermelon. The identified candidate genes were involved in metabolic pathways associated with amino acid metabolism, such as Argininosuccinate synthase, explaining 7\% of the variation in arginine content, which validate their functional relevance and potential for marker-assisted analysis selection. This studv provides a nlatform for exploring potential gene loci involved in seed-bound
Peer) reviewing PDF (2021:04:60681:1:2:NEW 20 Aug 2021) 
amino acids metabolism, useful in genetic analysis and development of watermelon varieties with superior seed nutritional values. 
1 Genome-wide association study and population structure

2 analysis of seed-bound amino acids and total protein in

3 watermelon

4

5

Vijay Joshi ${ }^{1,3 \uparrow *}$, Padma Nimmakayala ${ }^{2 \dagger}$, Qiushuo Song ${ }^{3, \dagger}$, Venkata Lakshmi Abburi², Purushothaman Natarajan ${ }^{2}$, Amnon Levi $^{4}$, Kevin Crosby ${ }^{3}$, and Umesh K. Reddy ${ }^{2 *}$

7

$8{ }^{1}$ Texas A\&M AgriLife Research and Extension Center, Uvalde, Texas, USA

9 2Department of Biology, Gus R. Douglass Institute, West Virginia State University, Institute, 10 West Virginia, USA

$11{ }^{3}$ Department of Horticultural Sciences, Texas A\&M University, College Station, Texas, USA

*Corresponding authors

1. Umesh K. Reddy

West Virginia State University, WV 25112. 141 Hamblin Hall Institute, West Virginia State University, WV 25112-1000

Email address: ureddy@wvstateu.edu

2. Vijay Joshi

1619 Garner Field Road, Texas A\&M AgriLife Research and Extension Center, Uvalde, Texas 78801- 1103

Email address: Vijay.Joshi@tamu.edu

$\dagger$ : Authors contributed equally.

\section{Abstract}

\section{Background}

Watermelon seeds are a powerhouse of value-added traits such as proteins, free amino acids, vitamins, and essential minerals, offering a paleo-friendly dietary option. Despite the availability of substantial genetic variation, there is no sufficient information on the natural variation in seedbound amino acids or proteins across the watermelon germplasm. This study aimed to analyze the natural variation in watermelon seed amino acids and total protein and explore underpinning genetic loci by genome-wide association study (GWAS).

\section{Methods}

The study evaluated the distribution of seed-bound free amino acids and total protein in 211 watermelon accessions of Citrullus spp, including 154 of Citrullus lanatus, 54 of Citrullus 
40 seed phenotypes with 11,456 single nucleotide polymorphisms (SNPs) generated by genotyping-

41 by-sequencing (GBS).

42 Results

43 Our results demonstrate a significant natural variation in different free amino acids and total

44 protein content across accessions and geographic regions. The accessions with high protein

45 content and proportion of essential amino acids warrant its use for value-added benefits in the

46 food and feed industries via biofortification. The GWAS analysis identified 188 SNPs coinciding

47 with 167 candidate genes associated with watermelon seed-bound amino acids and total protein.

48 Clustering of SNPs associated with individual amino acids found by principal component

49 analysis was independent of the speciation or cultivar groups and was not selected during the

50 domestication of sweet watermelon. The identified candidate genes were involved in metabolic

51 pathways associated with amino acid metabolism, such as Argininosuccinate synthase,

52 explaining $7 \%$ of the variation in arginine content, which validate their functional relevance and

53 potential for marker-assisted analysis selection. This study provides a platform for exploring

54 potential gene loci involved in seed-bound amino acids metabolism, useful in genetic analysis

55 and development of watermelon varieties with superior seed nutritional values.

56

\section{Introduction}

58 Nutritional improvement of crop plants is most critical for the overall health of people around the world. Proteins and their structural constituents, amino acids, are indispensable for human nutrition and health. Plant seeds store a wide range of compounds, such as proteins, free amino acids, carbohydrates, and storage lipids, contributing $\sim 70 \%$ of the world's human caloric intake directly or indirectly as animal feed (Sreenivasulu \& Wobus 2013). Furthermore, amino acids play vital roles in the central metabolism of seeds and are used to synthesize seed storage proteins as precursors for the biosynthesis of secondary metabolites and are catabolized via the tricarboxylic acid cycle to generate energy to support seedling growth (Amir et al. 2018; Angelovici et al. 2011; Galili et al. 2014). Humans and farm animals cannot synthesize many essential amino acids. Populations in lowincome countries that rely on a few selected crops with an imbalanced amino acid composition develop health problems due to essential amino acid deficiencies. Manufactured animal feed is augmented with chemically synthesized amino acids, which is cost-intensive. Hence, strategies to increase protein levels and the concentration of essential amino acids in food crops are of primary importance in most crop improvement programs. Several traditional and transgenic approaches have been successfully used to improve protein contents and amino acid balance in plant seeds (Chakraborty et al. 2010; Jiang et al. 2016; Newell-McGloughlin 2008). Watermelon seeds have been used as a principal staple food for native people in western Africa and the Sahara Desert (Jensen et al. 2011). The watermelon seeds are considered a potential powerhouse of proteins (30-35\%), oils, B vitamins, niacin, thiamin, and essential minerals such as iron, magnesium, manganese phosphorus, potassium, and zinc. Because of the high protein 
80 content, omega-3 and -6 fatty acids, micronutrients, and lack of oligosaccharides (leads to

81 flatulence in bean-based diets) (El-Adawy \& Taha 2001; Jyothi Lakshmi \& Kaul 2011;

82 Rakhimov et al. 1995; Wani et al. 2011b) and various essential amino acids and non-protein

83 amino acids (El-Adawy \& Taha 2001; Jyothi Lakshmi \& Kaul 2011), watermelon seeds offer a

84 paleo-friendly and gluten-free healthy dietary option. Arginine is one of the predominant amino

85 acids in watermelon seeds (Hartman et al. 2019; Perkins-Veazie et al. 2015).

86 Genetic screens with various approaches such as linkage mapping, quantitative trait loci, and

87 genome-wide association study (GWAS) have been used to genetically improve the

88

89

90

91

92

93

94

95

96

97

98

99

100

101

102

103

104

105

106

107

108

109

110

111

112

113

114

115

116

117

118

119 accumulation of nutritionally limiting seed-bound amino acids or proteins in soybean (Lee et al. 2019; Panthee et al. 2006; Warrington et al. 2015; Zhang et al. 2018), chickpea (Upadhyaya et al. 2016), maize (Deng et al. 2017) and Arabidopsis (Angelovici et al. 2013; Jander et al. 2004; Joshi et al. 2006). Despite the availability of substantial genetic variation, the genes regulating amino acids or protein content in watermelon seeds and the extent of variability for seed amino acids and total protein across watermelon germplasm have not been studied. In this study, genetic components underlying natural variation and amino acid metabolism in watermelon seeds have been elucidated. We evaluated total amino acid and protein content in seeds of accessions representing different Citrullus spp. of the germplasm collection available at the USDA germplasm repository. We conducted GWAS and identified single nucleotide polymorphism (SNP) markers associated with watermelon seed-specific amino acids and total protein. The candidate genes identified in this study provide insights into amino acid and protein biosynthesis and could be used in marker-assisted selection to improve the nutritional value of watermelon and cucurbit crop seeds.

\section{Materials \& Methods}

\section{Seed sample preparation}

Seeds of 154 Citrullus lanatus, 54 Citrullus mucosospermus, and 3 Citrullus amarus accessions obtained from the USDA Germplasm Resources Information Network were evaluated for amino acid content and total protein. The seed coats were removed by using pliers or nail clippers to recover the intact endosperms. Approximately $20 \mathrm{mg}$ and $10 \mathrm{mg}$ shelled watermelon seeds of each accession were placed in a 2-mL microcentrifuge tube in triplicate for amino acid and protein extraction. The samples were flash-frozen in liquid nitrogen and homogenized to a fine powder using $5 \mathrm{~mm}$ Demag stainless steel balls (Abbott Ball Co., CT, USA) in a Harbil model 5G-HD paint shaker.

\section{Amino acid extraction and analysis}

Amino acids were extracted using an established protocol (Joshi et al. 2019) by suspending the homogenized samples in $100 \mathrm{mM}$ cold $\mathrm{HCl}$ extraction buffer, then incubation on ice ( $20 \mathrm{~min})$ and centrifugation @ $14,609 \times \mathrm{g}$ for $20 \mathrm{~min}$ at $4{ }^{\circ} \mathrm{C}$. The supernatants were collected and filtered through a 96-well 0.45- $\mu$ m-pore filter plate (Pall Life Sciences, USA). The eluents collected in 96-well trap plates were stored at $-20^{\circ} \mathrm{C}$ for further amino acid quantification. The derivatization of filtrates was carried out using the AccQ $\bullet \mathrm{Tag}^{\mathrm{TM}} 3 \mathrm{X}$ Ultra-Fluor derivatization kit (Waters 
120 Corp., Milford, MA, USA) following the standard protocol. L-Norvaline (Sigma, St. Louis, MO) 121 was used as an internal standard. Amino acid calibration was performed using the Kairos ${ }^{\mathrm{TM}}$ 122 Amino Acid Kit (Waters Corp., Milford, MA, USA).

123 Calibration curves were built with the TargetLynx ${ }^{\mathrm{TM}}$ Application Manager (Waters Corp., 124 Milford, MA, USA). Amino acid detection was carried out using a Waters Acquity H-class 125 UPLC system equipped with Waters Xevo TQ mass spectrometer with an electrospray ionization

126

127

128

129

130

131

132

133

134

135

136

137

138

139

140

141

142

143

144

145

146

147

148

149

150

151

152

153

154

155

156

157

158

159 (ESI) probe. The Waters Acquity H-class UPLC system consists of an autosampler, a binary solvent manager, a column heater, and a Water's AccQ $•$ Tag Ultra column $(2.1 \mathrm{~mm}$ i.d. $\times 140$ $\mathrm{mm}, 1.7-\mu \mathrm{m}$ particles). The mobile phase consisted of a water phase (A) $(0.1 \%$ formic acid $\mathrm{v} / \mathrm{v})$ and acetonitrile (B) $(0.1 \%$ formic acid $\mathrm{v} / \mathrm{v})$ with a stable flow rate at $0.5 \mathrm{~mL} / \mathrm{min}$ and column temperature set at $55^{\circ} \mathrm{C}$. The gradient of non-linear separation was as follows: $0-1 \mathrm{~min}(99 \% \mathrm{~A})$, $3.2 \min (87.0 \% \mathrm{~A}), 8 \mathrm{~min}(86.5 \% \mathrm{~A})$, and $9 \min (5 \% \mathrm{~A})$. Finally, $2 \mu \mathrm{l}$ of the derivatized sample was injected into the column for analysis. IntelliStart software (Waters Corp., Milford, MA) was used to optimize each amino acid Multiple Reaction Monitoring (MRM) transition, collision energy values, and cone voltage. ESI source was set to $150{ }^{\circ} \mathrm{C}$ with gas desolvation flow rate $1000 \mathrm{~L} / \mathrm{h}$, gas flow cone $20 \mathrm{~L} / \mathrm{h}$, desolvation temperature $500^{\circ} \mathrm{C}$, capillary voltage $2.0 \mathrm{kV}$, gas collision energy 15 to $30 \mathrm{~V}$, and cone voltage $30 \mathrm{~V}$ for detecting all amino acids. Water's MassLynx ${ }^{\mathrm{TM}}$ software was used for instrument monitoring and data acquisition. The TargetLynx ${ }^{\mathrm{TM}}$ Application Manager (Waters Corp., Milford, MA, USA) was used for data integration, calibration curves, and amino acid quantification.

\section{Total protein extraction and analysis}

Total protein was extracted from homogenized seeds samples of each accession using an extraction buffer ( $70 \mathrm{mM}$ Tris $\mathrm{HCl}, 25 \mathrm{mM} \mathrm{KCl}, 1 \mathrm{mM} \mathrm{MgCl} 2,5 \mathrm{mM}$ EDTA, $5 \%$ glycerol, $0.1 \%$ Triton X-100, and $15 \mathrm{mM} \beta$-mercaptoethanol). The extracts were filtered using a 96-well 0.45$\mu \mathrm{m}$-pore filter plate (Pall Life Sciences, USA), and filtrates were used to determine protein content with the Bradford Protein Assay Kit (AMRESCO Inc.). Extracts of $20 \mu 1$ were incubated with $180 \mu \mathrm{l}$ buffer for $2 \mathrm{~min}$ in a 96-well microplate (F-bottom, Greiner Bio-One,

Kremsmünster, Austria) before measuring the absorbance at $595 \mathrm{~nm}$ in a spectrophotometer (Multiskan GO, Thermo Scientific, Waltham, MA, USA). Before measuring samples, $0.5 \mathrm{mg} / \mathrm{mL}$ BSA solution was used to prepare a standard curve to detect protein concentrations, and the total protein was reported as $\mu \mathrm{g}$ per mg of seed.

Statistical procedures such as ANOVA, Student t-Test, and the Principal component analysis (PCA) were performed using JMPR 15.2.0 (SAS Institute Inc., Cary, NC) statistical package.

\section{Association analysis}

For GWAS, the population structure Q matrix was replaced by the PC matrix. The PC matrix and identity by descent (IBD) were calculated by using the EIGENSTRAT algorithm (Patterson et al. 2006) with the SNP \& Variation Suite (SVS v8.8.1; Golden Helix, Inc., Bozeman, MT) in SVS v8.1.5. GWAS involved a multiple-locus mixed linear model developed by the EMMAX method and implemented in SVS v8.1.5. We used a PC matrix (first two vectors) and the IBD matrix to correct population stratification. Manhattan plots for associated SNPs were visualized in 
160 GenomeBrowse v1.0 (Golden Helix, Inc). The SNP P-values from GWAS underwent false

161

162

163

164

165

166

167

168

169

170

171

172

173

174

175

176

177

178

179

180

181

182

183

184

185

186

187

188

189

190

191

192

193

194

195

196

197

198

199

discovery rate (FDR) analysis. The details of 11,456 SNPs generated by genotype by sequencing (Nimmakayala et al. 2014; Wu et al. 2019) used for association analysis and resolving population structure are available as supplemental data with the cited papers.

\section{Population structure with associated SNPs}

To analyze the impact of amino acid accumulation in the global collection of cultivars and wild types on population structure, we generated the principal components, or eigenvectors, by principal component analysis (PCA) and corresponding eigenvalues were estimated by the associated SNPs.

\section{Results}

\section{Phenotypic variation in the seed-bound free amino acids and total protein}

We investigated the distribution of seed amino acids in 211 watermelon accessions, including 154 of Citrullus lanatus, 54 of Citrullus mucosospermus (egusi), and 3 of Citrullus amarus. We detected 28 amino acids, including 20 protein-bound and 8 non-protein amino acids (such as GABA, citrulline, ornithine) in the seeds of all watermelon accessions. Nitrogen-rich amino acids such as glutamic acid (29.6\%), followed by arginine (17.9\%), aspartic acid $(9.7 \%)$, and alanine (7.6\%) were the most abundant amino acids in watermelon seeds (Fig. 1). ANOVA confirmed a significant variation in the seed-bound free amino acids and total protein $(\mathrm{P}<0.05)$. Amino acids and the total protein content of seeds are influenced by genetic backgrounds, geographic origin, species, agronomic conditions, and postharvest processing. The percent distribution of all seed-bound amino acids is presented in Table S1. The highest proportion of arginine (40.6\%) and citrulline (18.1\%) in seeds was measured in accessions PI 470246 (C. lanatus) and PI 254740 (C. mucosospermus), respectively. The details of geographical origin and continents are in Table $S 2$. We found significant differences in the proportion of the most abundant amino acids (glutamic acid, arginine, aspartic acid, and alanine) across continents and species (Fig. S1-to Fig. S4). For example, glutamate content was significantly lower in European than North American and Asian accessions. Likewise, African accessions showed the lowest arginine content compared with European and North American accessions. Aspartic acid and alanine content were highest in African and South American accessions, respectively. Similarly, glutamate and arginine contents were high in C. mucosospermus, whereas C. lanatus accessions had high aspartic acid and alanine contents. The percentages of free amino acids were submitted to the principal component analysis (PCA), which revealed a clear separation of $C$. mucosospermus and the African continent. The first two principal components accounted for $35.6 \%$ of the total variance in the data, of which PC1 explained $23.3 \%$ of this variance and PC2 explained $12.2 \%$ (Fig. S5). The amino acids such as branched-chain amino acids (Isoleucine, Leucine, valine), proline, asparagine, and alanine contributed positively to the construction of PC1. In contrast, glutamate, arginine, aspartate citrulline contributed negatively to construct PC1. Furthermore, glutamate, aspartate, and argininosuccinic acid contributed positively to construct PC2, whereas arginine, histidine, citrulline, and ornithine contributed negatively.

Peer) reviewing PDF | (2021:04:60681:1:2:NEW 20 Aug 2021) 
200 The percentage protein distribution across accessions is in Figure 2. The accession PI 172799 201 had the highest seed protein content (19.5\%). The crude seed protein content in the commercial 202 cultivars (Black Diamond, Charleston Gray, and Crimson Sweet) has ranged from 16\% to 17.7\% 203 (Tabiri 2016). The mean protein content across accessions by continent is provided in Table S3. 204 The mean protein content in accessions was significantly higher in Europe (11.5\%) and Africa $205(11.3 \%)$ than Asia (10.6\%) and North America (10.5\%). The distribution of protein content in $C$. 206 lanatus, C. mucosospermus, and C. amarus is summarized in Fig. S6. The mean protein content 207 was comparable in C. mucosospermus (11.4\%) and C. lanatus $(11.0 \%)$ and C. amarus $(10.3 \%)$. 208 Overall population structure

209 We used 11,456 SNPs generated by genotype by sequencing (Nimmakayala et al. 2014; Wu et 210 al. 2019) for resolving population structure. Principal component analysis (PCA) separated 211 ancestral species C. mucasospermous (egusi), C. lanatus (wild, landrace, and cultivars) into two 212 groups. The C. lanatus group showed an admixture of wild, landrace (semi-wild), and cultivars 213 (Fig. 3A). Many cultivars formed as a single cluster. This PCA was superimposed with arginine 214 content to understand clustering across accessions during breeding histories for arginine content. 215 Egusi types, wild lanatus, landraces, and cultivars possessed low, medium, and high arginine 216 content in all taxa in the study (Fig. 3B). Hence, we did not notice any selection for arginine 217 during the domestication of sweet watermelon.

218 GWAS for various amino acid and total protein content

219 Our GWAS associated 4, 22, 11, 19, 6, 12, 6, 30, 3, 10, 5, 14, 12, 13, 8, 3, 5, 8, 7, 11, 5, 4, 6, 11, $22014,5,8$ and 7 SNPs with histidine, arginine, asparagine, glutamine, serine, glutamic acid, 221 aspartic acid, citrulline, threonine, glycine, alanine, GABA, proline, L-ornithine, cystine, lysine, 222 tyrosine, methionine, valine, isoleucine, leucine, phenylalanine, ethanolamine, hydroxylysine, 223 alpha aminoadipic acid, kynurenine, tryptophan, and arginine succinic acid, respectively. We 224 present association statistics indicating chromosomal location, significance, FDR, regression beta 225 226

227

228

229 (positive or negative), the standard deviation of regression beta, sample size, call rate, phenotypic variance explained by the SNP, minor allele frequencies of associated SNPs, type of mutation, gene name, gene region, and harboring these SNPs for all detected amino acids in Table S4 and total protein in Table S5. Manhattan plots showing chromosome distribution of

230 associations for 24 seed-bound free amino acids and total protein are in Figures 4 through 11 and 231 Figure 12, respectively. Quantile-quantile (Q-Q) plots for various amino acids and total proteins

232 are in shown Fig. $S 7$ and Fig. S8, respectively.

233 Population structure analysis based on associated SNPs for amino acids and total protein We used PCA with associated SNPs for each amino acid and total protein content in the study.

235 The PCA revealed how associated SNPs representing causative genes distort the population

236

237 structure compared with the overall population structure. The first two eigenvectors of PCA cumulatively explained the percentage variation absorbed by each amino acid (Fig. S9) and total protein (Fig. S10). Our study revealed associated SNPs when used for PCA analysis, individual 238 239 PCA for histidine, arginine, asparagine, glutamine, serine, glutamic acid, aspartic acid, citrulline, threonine, glycine, alanine, GABA, proline, L-ornithine, cystine, lysine, tyrosine, 
240 methionine, valine, isoleucine, leucine, phenylalanine, ethanolamine, hydroxylysine, alpha

241 aminoadipic acid, kynurenine, tryptophan, and arginine succinic acid absorbed 57\%, 45\%, 32\%,

$24259 \%, 47 \%, 26 \%, 50 \%, 21 \%, 85 \%, 26 \%, 35 \%, 34 \%, 36 \%, 29 \%, 35 \%, 26 \%, 60 \%, 29 \%, 30 \%$,

$24351 \%, 22 \%, 57 \%, 51 \%$ and 52\%, respectively of total genetic variance. PCA with associated

244 SNPs for serine, aspartic acid, threonine, lysine, phenylalanine, kynurenine, tryptophan, and

245 arginine succinic acid divided the population into three distinct clusters, although the clustering

246 was independent of the speciation or cultivar groups. None of the seed-bound amino acid

247 components was selected during the domestication of sweet watermelon. Because the

248 domestication of sweet watermelon is based on fruit size, rind thickness, flesh softening, and

249 soluble solids, seed composition may not have been directly or indirectly under selection.

250 Genes under association

251 Detailed annotation for the genes identified for various metabolites in the current GWAS is in

252 Table S4. Among the genes identified by GWAS that were common to various metabolites, the

253 gene most directly and highly associated with various metabolites was a nonsynonymous SNP

254 (S2_9832702) located in ATP-binding cassette (ABC) transporter B family member 19

255 (ABCB19; ClCG02G007990), located on chromosome 2 and showing multiple significant

256 associations with alpha aminoadipic acid $(\mathrm{p}=0.00000004)$, glutamine $(\mathrm{p}=0.0002)$, glycine

257 ( $\mathrm{p}=0.000004)$, GABA $(\mathrm{p}=0.000004)$, proline $(\mathrm{p}=0.0002)$, lysine $(\mathrm{p}=0.000027)$, valine $(\mathrm{p}=$

258 0.000006), leucine (0.000003), isoleucine $(\mathrm{P}=0.000000006)$, ethanolamine $(\mathrm{P}=0.0002)$,

259 cysteine $(\mathrm{p}=0.000005)$ and alpha aminoadipic acid $(\mathrm{p}=0.00000004)$, which explained 9\%, 10\%,

$2608 \%, 11 \%, 7 \%, 9 \%, 11 \%, 9 \%, 8 \%, 5 \%, 7 \%$ and $11 \%$ of the phenotypic variance, respectively.

261 This gene is known for mediating the polar transport of auxin and is required to establish an

262 auxin concentration gradient, which is essential for cytoplasmic streaming that may have a role

263 in seed development.

264 Argininosuccinate synthase (ClCG03G003660), located on chromosome 3 ( $\mathrm{p}=0.0008$ FDR

265 0.003), explained 7\% of the variance for both arginine and argininosuccinic acid. Arogenate

266 dehydrogenase (TyrA/ADH; ClCG11G003430), on chromosome 11, was strongly associated with

267 arginine $(\mathrm{p}=0.00009)$, tyrosine $(\mathrm{p}=0.0005)$ and argininosuccinic acid $(\mathrm{p}=0.0003) . \mathrm{S} 7 \_7819769$,

268 an exonic located in sspartate semialdehyde dehydrogenase (ClCG07G005480), was associated

269 with asparagine $(\mathrm{P}=0.0005)$, explaining $7 \%$ of the variance.

270 A haplotype with two SNPs in aspartate/tyrosine/aromatic aminotransferase (ClCG11G013620)

271 was associated with alanine $(\mathrm{p}=0.00002)$, explaining $9 \%$ of the variance; tyrosine $(\mathrm{p}=0.0007)$,

$2727 \%$; and asparagine ( $\mathrm{p}=0.0000000001), 10 \%$ of the variance. Tyrosine aminotransferase was

273 significantly associated with arginine, alpha aminoadipic acid, glutamic acid, asparagine,

274 alanine, L-ornithine, and tyrosine.

275 A strong haplotype encompassing S2_1683683 to S2 1683687 with five SNPs is located in

276 pentatricopeptide repeat protein 65 (ClCG02G001590), associated with glutamine $(\mathrm{p}=0.0002)$,

277 explaining $8 \%$ of the variance. This gene was also significantly associated with citrulline $(\mathrm{p}=$

$2780.0001)$, proline $(\mathrm{p}=0.001)$, GABA $(\mathrm{p}=0.0001)$, lysine $(\mathrm{p}=0.0009)$ and alpha aminoadipic

279 acid $(\mathrm{p}=0.0001)$.

Peer] reviewing PDF | (2021:04:60681:1:2:NEW 20 Aug 2021) 
280 Another haplotype on chromosome 11 located in glutamine--tRNA ligase (ClCG11G004350) has 281 three SNPs associated with citrulline $(\mathrm{p}=0.0004)$.

282 ABA-responsive element-binding factor 2 (ClCG08G016000) was associated with serine $(\mathrm{p}=$ $2830.001)$, explaining $7 \%$ of the variance; glycine $(\mathrm{p}=0.0001), 9 \%$; proline $(\mathrm{p}=0.0000001), 12 \%$; 284 and valine $(\mathrm{p}=0.0007), 7 \%$.

285 Acyl-[acyl-carrier-protein] desaturase was associated in the synthesis of citrulline $286(\mathrm{p}=0.0000001)$, explaining $13 \%$ of the variance; glycine $(\mathrm{p}=0.0001), 5 \%$; L-ornithine $287(p=0.0005), 8 \%$; lysine $(p=0.0004), 8 \%$; and glutamic acid $(p=0.0008) 5 \%$.

288 Different ankyrin-repeat family proteins were associated with aspartic acid $(\mathrm{p}=1.29 \mathrm{E}-06)$, 289 explaining $10 \%$ of the variance; arginine $(\mathrm{p}=0.0004), 8 \%$; and total protein $(\mathrm{p}=5.23 \mathrm{E}-08), 8 \%$. 290 Arogenerate dehydrogenase was associated with arginine $(\mathrm{p}=9.21 \mathrm{E}-05)$, explaining $3 \%$ of the 291 variance; tyrosine ( $\mathrm{p}=0.0006), 7 \%$; and argininosuccinic acid $(\mathrm{p}=0.0003), 5 \%$.

292 E3 ubiquitin-protein ligase UPL3 (ClCG02G011880) was associated with the synthesis of 293 methionine $(p=1.93 \mathrm{E}-08)$, explaining $8 \%$ of the variance; valine $(\mathrm{p}=0.0009), 7 \%$; isoleucine $294(p=3.29 E-07), 8 \%$; ethanolamine $(p=8.17 \mathrm{E}-05), 8 \%$; and alpha aminoadipic acid $(\mathrm{p}=0.0003), 8 \%$. 295 Endo-1,3,1,4 beta-d-glucanase was associated with threonine $(p=0.0006)$, explaining $7 \%$ of the 296 variance; L-ornithine $(\mathrm{p}=0.0008), 7 \%$; and tyrosine $(\mathrm{p}=0.0008), 7 \%$.

297 DNA-directed RNA polymerase was associated with arginine $(\mathrm{p}=4.73 \mathrm{E}-05)$, explaining $6 \%$ of 298 the variance; citrulline $(p=2.92 \mathrm{E}-06), 12 \%$; asparagine $(\mathrm{p}=6.36 \mathrm{E}-05), 5 \%$; serine $(\mathrm{p}=8.69 \mathrm{E}-0)$, $2999 \%$; glycine ( $p=2.67 \mathrm{E}-07), 10 \%$; tyrosine $(\mathrm{p}=5.10 \mathrm{E}-06), 9 \%$; and methionine $(\mathrm{p}=0.0008), 7 \%$. 300 E3 ubiquitin-protein ligase UPL3 was associated with methionine ( $\mathrm{p}=1.93 \mathrm{E}-08)$, explaining $8 \%$ 301 of the variance; valine $(\mathrm{p}=0.001), 7 \%$; isoleucine $(\mathrm{p}=3.29 \mathrm{E}-07), 7 \%$; ethanolamine $(\mathrm{p}=8.17 \mathrm{E}-05)$, $30210 \%$; and alpha aminoadipic acid $(\mathrm{p}=0.0004), 8 \%$.

303 GATA transcription factor (ClCG10G013320) was associated with arginine $(\mathrm{p}=0.0007)$, 304 explaining $7 \%$ of the variance; glutamine ( $p=0.0005), 8 \%$; and citrulline ( $\mathrm{p}=6.78 \mathrm{E}-06), 12 \%$. 305 Leucine-rich receptor-like protein kinase was associated with citrulline $(\mathrm{p}=6.15 \mathrm{E}-07)$, explaining $30614 \%$ of the variance; L-ornithine $(\mathrm{p}=0.0003), 18 \%$; and argininosuccinic acid $(\mathrm{p}=3.96 \mathrm{E}-06)$, $3078 \%$.

308 Oleosin, the putative gene, was associated with asparagine ( $\mathrm{p}=0.0003)$, explaining $8 \%$ of the 309 variance; glutamine $(\mathrm{p}=0.0004), 8 \%$; and L-ornithine $(0.0006), 7 \%$.

310 Zinc finger family protein was associated with glutamine $(\mathrm{p}=0.0001)$, explaining $9 \%$ of the 311 variance; glutamic acid ( $\mathrm{p}=2.24 \mathrm{E}-05), 4 \%$; argininosuccinic acid $(\mathrm{p}=0.001), 7 \%$; arginine $312(p=0.0001), 9 \%$; aspargine $(p=1.18 \mathrm{E}-05), 5 \%$; L-ornithine $(p=4.36 \mathrm{E}-05), 7 \%$; citrulline $313(p=6.42 \mathrm{E}-05), 10 \%$; tryptophan $(p=5.31 \mathrm{E}-05), 10 \%$; aspargine $(p=0.0006), 7 \%$; alanine $314(p=2.72 \mathrm{E}-05), 7 \%$; total protein $(p=0.0004), 8 \%$; and hydroxylysine $(p=1.45 \mathrm{E}-06), 8 \%$.

315 Transmembrane protein adipocyte-associated-1 homolog was significantly associated with 316 glycine ( $\mathrm{p}=0.0003)$, explaining $8 \%$ of the variance; alanine ( $\mathrm{p}=0.0009), 7 \%$; and valine $317(\mathrm{p}=0.0003), 8 \%$. TOM1-like protein 2 was significantly associated with asparagine $(\mathrm{p}=4.67 \mathrm{E}-$ $31809)$, explaining $9 \%$ of the variance; glutamic acid $(p=0.0002) 9 \%$; threonine $(p=0.0007), 7 \%$; 319 glycine $(p=6.30 \mathrm{E}-07), 6 \%$; tyrosine $(p=0.0005), 5 \%$; and valine $(p=3.23 \mathrm{E}-05), 10 \%$. 
320

321

322

323

324

325

326

327

328

329

330

331

332

333

334

335

336

337

338

339

340

341

342

343

344

345

346

347

348

349

350

351

352

353

354

355

356

357

358

\section{Nucleotide diversity and Tajima's $D$ for various amino acids}

We estimated nucleotide diversity ( $\pi$ and $\Theta$ ) and Tajima's D using the associated SNPs for various metabolites estimated in the current study (Table 1). These parameters were separately estimated for wild and cultivated watermelon. None significantly differed between wild and cultivated varieties, which indicated that the genetic mechanisms underlying seed-bound amino acids might not undergo any selection during domestication.

\section{Discussion}

The current study explored natural variation for various seed amino acids and provides a list of cultivars, landraces, and egusi lines with high amino acid content for potential use in breeding programs. Watermelon seed proteins and free amino acids are among the most tangible paleofriendly, nitrogen-rich, gluten-free dietary options. Seeds of egusi cultivars are a significant part of the diet in many African countries (Giwa \& Akanbi 2020). Giwa and Akanbi (2020) reviewed various reports indicating egusi melon seed kernels are a good source of edible oil (31-59\%), protein (19-37\%), fiber (3-4\%), and carbohydrate (8-20\%). A coarse whitish meal of grounded seed kernel of egusi is used to make nutritious and pleasantly nutty-tasting (Oke 1965). A detailed metabolic landscape of watermelon seeds using the diversity panel such as the current study would help identify genetic loci and parental lines to develop value-added seeded varieties to promote seeds for human consumption and culinary use (food additives) and livestock consumption.

Nutritionally superior seeds can be developed by identifying and deploying the gene(s)/QTLs associated with seed-specific nutraceuticals. Understanding genetic and molecular regulation of seed-specific proteins would help identify targets for developing protein-rich food options. GWAS and QTL mapping has been used to analyze seed-specific protein, oil, fatty acid, and amino acid content in various crops such as soybean (Hwang et al. 2014; Lee et al. 2019; Zhang et al. 2019), chickpea (Upadhyaya et al. 2016), peanut (Gangurde et al. 2020) rice (Chen et al. 2018), cotton (Yuan et al. 2018), and maize (Cook et al. 2011). Although it is hard to generalize the outcomes due to the species-level differences in the protein quality and composition, these studies have allowed the identification of SNPs and unique biomarkers linked to QTL for genome manipulation, germplasm enhancement, and the creation of high-density gene libraries. This study performed GWAS of amino acids in watermelon seed to efficiently identify genetic loci influencing amino acid profiles in watermelon and underlying candidate genes and networks. We used significantly associated SNPs for these amino acids to explore the population structure and compared them with the genome-wide population structure to understand whether the genetic mechanisms underlying various amino acid metabolism had no role in the domestication of sweet watermelon. Furthermore, nucleotide diversities and Tajima's D estimated for the SNPs underlying the composition of amino acids did not differ between wild and cultivated watermelon genotypes, so seed amino acid profiles were not involved in domestication. 
359

360

361

362

363

364

365

366

367

368

369

370

371

372

373

374

375

376

377

378

379

380

381

382

383

384

385

386

387

388

389

390

391

392

393

394

395

396

397

398

Although GWAS identified genes with strong associations with more than one metabolite, we explored genes with known roles in regulating these metabolites. The most intriguing nonsynonymous SNP in ABCB19 (ClCG02G007990) was associated with multiple amino acids such as alpha aminoadipic acid, glutamine, GABA, proline, lysine, valine, leucine, isoleucine, ethanolamine, and alpha aminoadipic acid. The encoded protein is conserved across Cucurbits and shares more than $67 \%$ identity with several plant species such as cotton, Medicago, and chickpea. Members of the $\mathrm{ABC}$ transporter superfamily transport a wide range of molecules across various membrane types (Do et al. 2018) and play an essential role in seed development, seed germination, organ formation, and secondary growth (Hwang et al. 2016). Regulation of ABCB19 involves intricate coordinated cellular processes, including protein-protein interactions, vesicular trafficking, protein phosphorylation, ubiquitination, and stabilization of the transporter complexes (Titapiwatanakun \& Murphy 2009). Establishing an auxin concentration gradient is required, which is essential for cytoplasmic streaming (Peer et al. 2014).

The tyrosine aminotransferase (TAT, ClCG11G017780), associated with multiple amino acids, represents the entry point for various tyrosine degradation of natural products' biosynthesis in the recycling of energy and nutrients in plants (Wang et al. 2019). The Arabidopsis ortholog of this gene is induced under conditions leading to oxidative stress and senescing leaves, developing seeds, and ABA treatment (Holländer-Czytko et al. 2005; Winter et al. 2007).

Similarly, the orthologs of the basic leucine zipper transcription factor ABA-responsive element binding factor 2, with multiple associations with amino acids, is a positive regulator of glucose signal transduction and upregulates ABA-responsive gene expression (Cutler et al. 2010). Besides modulating various plant developmental processes, ABA regulates seed maturation, dormancy, and germination (Choi et al. 2000). E3 ubiquitin-protein ligase UPL3 (ClCG02G011880) identified in this study encodes an ortholog of Arabidopsis (Downes et al. 2003) and Brassica miller (Miller et al. 2019) E3 ligase UPL3. Brassica UPL3 modulates seed size and lipid content and is exploited to increase yield. GATA transcription factor (ClCG10G013320) associated with arginine glutamine and citrulline suggests its involvement in regulating plant nitrogen metabolism. Several studies support GATA transcription factors' involvement in regulating nitrogen metabolism and amino acid-related genes in fungi and plants (Fu \& Marzluf 1990; Hudson et al. 2011; Rastogi et al. 1997; Shin et al. 2017).

Argininosuccinate synthase or synthetase (ASS; EC 6.3.4.5) regulates the antepenultimate step in arginine synthesis that catalyzes argininosuccinate synthesis from citrulline and aspartate. The progressive downregulation of three argininosuccinate synthases (ASS-1, ASS-2, and ASS-3) has been demonstrated in developing flesh and rind tissues from watermelon to accumulate free citrulline (Guo et al. 2013; Joshi et al. 2019; Zhu et al. 2017). However, citrulline content was relatively lower than arginine in mature seeds, implying deregulation of citrulline catabolism in seeds. According to the distribution of the seed-specific free (Joshi et al. 2019; Perkins-Veazie et al. 2015) and protein-bound amino acids (Wani et al. 2011a) in watermelon, arginine is one of the most abundant amino acid residues in the storage proteins. Arginine has the highest nitrogen- 
399 to-carbon ratio and is suitable as a storage form of organic nitrogen in seeds. About $40 \%$ to $50 \%$ 400 of the total nitrogen reserve in various plants is represented by arginine (Aninbon et al. 2017; 401 Cortés-Giraldo et al. 2016; de Ruiter \& Kollöffel 1983; King \& Gifford 1997; Micallef \& Shelp 402 1989b). Arginine plays a crucial role in nitrogen distribution and recycling (Slocum 2005) and 403 affects the synthesis of storage proteins critical for germination. In pea seeds, argininosuccinate 404 synthetase activity was significantly increased during the first weeks after anthesis, peaking at 405 about 35 days and decreasing progressively until 54 days (de Ruiter \& Kollöffel 1983), which 406 indicates its prominent role in arginine synthesis in seeds. Similarly, validation of $72 \%$ of 407

408

409

410

411

412

413

414

415

416

417

418

419

420

421

422

423

424

425

426

427

428

429

430

431

432

433

434

435

436

437 arginine requirement in developing soybean cotyledons by in situ biosyntheses (Micallef \& Shelp 1989b) and recovery of labeled arginosuccinate (Micallef \& Shelp 1989a) further support the functional role of arginine biosynthetic enzymes in seeds.

Arogenate dehydrogenase (TyrA/ADH; ClCG11G003430) was associated with arginine. In plants, the amino acid tyrosine is synthesized from arogenate by an enzyme arogenate dehydrogenase (TyrA). TyrA activity has been demonstrated in several plants (Byng et al. 1981; Connelly \& Conn 1986; Gaines et al. 1982; Rippert et al. 2009). Tyrosine is an essential aromatic amino acid required to synthesize proteins and serves as a precursor of several secondary metabolites families, including tocochromanols (vitamin E) and plastoquinones isoquinoline alkaloids and non-protein amino acids (Tzin \& Galili 2010). In maize kernels, reduction in abundance or activity of arogenate dehydrogenase reduced the zein protein synthesis rate (Holding et al. 2010). The broader impact of TyrA arogenate dehydrogenases on plant growth and development and seed yield was validated in Arabidopsis (de Oliveira et al. 2019). Another important gene from this GWAS is the aspartate semialdehyde dehydrogenase (ClCG07G005480), regulating the master aspartate pathway that leads to the synthesis of lysine methionine and threonine (Jander \& Joshi 2009). Although little is known about this gene's functional significance in plants, its unique place in the aspartate master pathway is indispensable for synthesizing downstream limiting amino acids. Consistent with this concept, increased aspartate semialdehyde content in transgenic rice seeds overexpressing feedbackinsensitive aspartate kinase $(A K)$ was converted to homoserine and threonine in seeds (Long et al. 2013), which suggests the role of this gene as a gatekeeper for regulating the synthesis of threonine, methionine, or lysine.

Because the current GWAS involved relatively few SNPs, it is limited in identifying long haplotypes involving candidate genes. Nonetheless, this study identified a long haplotype in pentatricopeptide repeat protein $65(P P R, \mathrm{ClCG} 02 \mathrm{G} 001590)$ with a highly significant association with glutamine as well as four other amino acids. Mutant analysis in Arabidopsis validated that PPR proteins significantly impact seed development and plant growth (de Longevialle et al. 2007) and maize (Gutiérrez-Marcos et al. 2007; Manavski et al. 2012). Recently, a defective kernel maize mutant Dek53 encoding a PPR protein with lethal embryo and collapsed endosperm function was characterized in maize (Dai et al. 2020) confirms the PPR role in seed development. 
438

439

440

441

442

443

444

445

446

447

448

449

450

451

452

453

454

455

456

457

458

459

460

461

462

463

464

465

466

467

468

469

470

471

472

473

474

475

476

477

478

In our GWAS analysis of total seed protein, the study identified a gene (ClCG03G016270) annotated as late embryogenesis abundant (LEA) protein. This protein's amino acid sequence shares high homology $(>90 \%)$ with other known LEA proteins in plants. LEA proteins accumulate to high levels during the last stage of seed formation (Hundertmark \& Hincha 2008) and play various roles, especially induction during water deficit (Tunnacliffe \& Wise 2007). LEA proteins also play a crucial role in normal seed development and plant growth (Manfre et al. 2006). Recently, the presence of the seed maturation protein domain and a progressive increase in the expression of this gene (ClLEA-25; Cla011279) during fruit maturation was validated in watermelon (Celik Altunoglu et al. 2017).

\section{Conclusions}

Watermelon seeds are a staple food for people in different parts of the world. Watermelon seed proteins and free amino acids contribute to the most tangible paleo-friendly protein-rich and gluten-free dietary options. Our results demonstrate a significant natural variation in different free amino acids and total protein content across accessions and geographic regions. The accessions with high protein content and a proportion of essential amino acids can be used for value-added benefits in the food and feed industries via biofortification. This study is the first to reveal the genetic architecture of seed-bound amino acids in a watermelon GWAS of 211 diverse accessions of Citrullus spp. with 11,456 SNPs generated by genotyping by sequencing (GBS) analysis. The GWAS identified quantitative gene loci (QTL) and several candidate genes involved in the metabolism of individual amino acids. The candidate genes identified here could help study the seed-bound amino acid accumulation, facilitate marker-assisted selection and provide novel targets for editing to accelerate nutrigenomics and associated breeding programs.

\section{Acknowledgments}

We appreciate Ms. Tatum Story for her assistance in sample preparation for metabolic analysis.

\section{References}

Amir R, Galili G, and Cohen H. 2018. The metabolic roles of free amino acids during seed development. Plant Science 275:11-18. https://doi.org/10.1016/j.plantsci.2018.06.011

Angelovici R, Fait A, Fernie AR, and Galili G. 2011. A seed high-lysine trait is negatively associated with the TCA cycle and slows down Arabidopsis seed germination. New Phytologist 189:148-159. 10.1111/j.1469-8137.2010.03478.x

Angelovici R, Lipka AE, Deason N, Gonzalez-Jorge S, Lin H, Cepela J, Buell R, Gore MA, and DellaPenna D. 2013. Genome-wide analysis of branched-chain amino acid levels in Arabidopsis seeds. The Plant cell 25:4827-4843.

Aninbon C, Jogloy S, Vorasoot N, Nuchadomrong S, Holbrook CC, Kvien C, Puppala N, and Patanothai A. 2017. Variability of arginine content and yield components in Valencia peanut germplasm. Breeding science 67:207-212. 10.1270/jsbbs.16146

Byng G, Whitaker R, Flick C, and Jensen RA. 1981. Enzymology of 1-tyrosine biosynthesis in corn (zea ma ys). Phytochemistry 20:1289-1292. 
479

480

481

482

483

484

485

486

487

488

489

490

491

492

493

494

495

496

497

498

499

500

501

502

503

504

505

506

507

508

509

510

511

512

513

514

515

516

517

518

519

520

521

522

523
Celik Altunoglu Y, Baloglu MC, Baloglu P, Yer EN, and Kara S. 2017. Genome-wide identification and comparative expression analysis of LEA genes in watermelon and melon genomes. Physiology and molecular biology of plants : an international journal of functional plant biology 23:5-21. 10.1007/s12298-016-0405-8

Chakraborty S, Chakraborty N, Agrawal L, Ghosh S, Narula K, Shekhar S, Naik PS, Pande PC, Chakrborti SK, and Datta A. 2010. Next-generation protein-rich potato expressing the seed protein gene $<\mathrm{em}>\mathrm{AmA} 1</ \mathrm{em}>$ is a result of proteome rebalancing in transgenic tuber. Proceedings of the National Academy of Sciences 107:17533-17538. 10.1073/pnas.1006265107

Chen P, Shen Z, Ming L, Li Y, Dan W, Lou G, Peng B, Wu B, Li Y, Zhao D, Gao G, Zhang Q, Xiao J, Li X, Wang G, and He Y. 2018. Genetic Basis of Variation in Rice Seed Storage Protein (Albumin, Globulin, Prolamin, and Glutelin) Content Revealed by Genome-Wide Association Analysis. Frontiers in plant science 9. 10.3389/fpls.2018.00612

Choi H-i, Hong J-h, Ha J-o, Kang J-y, and Kim SY. 2000. ABFs, a Family of ABA-responsive Element Binding Factors *. Journal of Biological Chemistry 275:1723-1730. 10.1074/jbc.275.3.1723

Connelly JA, and Conn EE. 1986. Tyrosine biosynthesis in Sorghum bicolor: isolation and regulatory properties of arogenate dehydrogenase. Zeitschrift für Naturforschung $C$ 41:69-78.

Cook JP, McMullen MD, Holland JB, Tian F, Bradbury P, Ross-Ibarra J, Buckler ES, and FlintGarcia SA. 2011. Genetic Architecture of Maize Kernel Composition in the Nested Association Mapping and Inbred Association Panels Plant physiology 158:824-834. 10.1104/pp.111.185033

Cortés-Giraldo I, Megías C, Alaiz M, Girón-Calle J, and Vioque J. 2016. Purification of free arginine from chickpea (Cicer arietinum) seeds. Food Chem 192:114-118. 10.1016/j.foodchem.2015.07.001

Cutler SR, Rodriguez PL, Finkelstein RR, and Abrams SR. 2010. Abscisic acid: emergence of a core signaling network. Annual Review of Plant Biology 61:651-679.

Dai D, Jin L, Huo Z-z, Yan S-m, Ma Z, Qi W, and Song R. 2020. Pentatricopeptide repeat protein DEK46 is required for multi-sites mitochondrial RNA editing and maize seed development. Journal of experimental botany.

de Longevialle AF, Meyer EH, Andrés C, Taylor NL, Lurin C, Millar AH, and Small ID. 2007. The pentatricopeptide repeat gene OTP43 is required for trans-splicing of the mitochondrial nad1 Intron 1 in Arabidopsis thaliana. The Plant cell 19:3256-3265. $10.1105 /$ tpc. 107.054841

de Oliveira MVV, Jin X, Chen X, Griffith D, Batchu S, and Maeda HA. 2019. Imbalance of tyrosine by modulating TyrA arogenate dehydrogenases impacts growth and development of Arabidopsis thaliana. Plant J 97:901-922. 10.1111/tpj.14169

de Ruiter H, and Kollöffel C. 1983. Arginine catabolism in the cotyledons of developing and germinating pea seeds. Plant physiology 73:525-528.

Deng M, Li D, Luo J, Xiao Y, Liu H, Pan Q, Zhang X, Jin M, Zhao M, and Yan J. 2017. The genetic architecture of amino acids dissection by association and linkage analysis in maize. Plant biotechnology journal 15:1250-1263. 10.1111/pbi.12712

Do THT, Martinoia E, and Lee Y. 2018. Functions of ABC transporters in plant growth and development. Curr Opin Plant Biol 41:32-38. 10.1016/j.pbi.2017.08.003

Peer] reviewing PDF | (2021:04:60681:1:2:NEW 20 Aug 2021) 
524 Downes BP, Stupar RM, Gingerich DJ, and Vierstra RD. 2003. The HECT ubiquitin-protein

525

526

527

528

529

530

531

532

533

534

535

536

537

538

539

540

541

542

543

544

545

546

547

548

549

550

551

552

553

554

555

556

557

558

559

560

561

562

563

564

565

566

567

568 ligase (UPL) family in Arabidopsis: UPL3 has a specific role in trichome development. Plant J 35:729-742. 10.1046/j.1365-313x.2003.01844.x

El-Adawy TA, and Taha KM. 2001. Characteristics and composition of different seed oils and flours. Food Chemistry 74:47-54. https://doi.org/10.1016/S0308-8146(00)00337-X

$\mathrm{Fu} \mathrm{YH}$, and Marzluf GA. 1990. nit-2, the major nitrogen regulatory gene of Neurospora crassa, encodes a protein with a putative zinc finger DNA-binding domain. Molecular and Cellular Biology 10:1056-1065.

Gaines C, Byng G, Whitaker R, and Jensen R. 1982. L-Tyrosine regulation and biosynthesis via arogenate dehydrogenase in suspension-cultured cells of Nicotiana silvestris Speg. et Comes. Planta 156:233-240.

Galili G, Avin-Wittenberg T, Angelovici R, and Fernie AR. 2014. The role of photosynthesis and amino acid metabolism in the energy status during seed development. Frontiers in plant science 5:447-447. 10.3389/fpls.2014.00447

Gangurde SS, Wang H, Yaduru S, Pandey MK, Fountain JC, Chu Y, Isleib T, Holbrook CC, Xavier A, Culbreath AK, Ozias-Akins P, Varshney RK, and Guo B. 2020. Nestedassociation mapping (NAM)-based genetic dissection uncovers candidate genes for seed and pod weights in peanut (Arachis hypogaea). Plant biotechnology journal 18:14571471. https://doi.org/10.1111/pbi.13311

Giwa SO, and Akanbi TO. 2020. A Review on Food Uses and the Prospect of Egusi Melon for Biodiesel Production. BioEnergy Research 13:1031-1045. 10.1007/s12155-020-10145-4

Guo SG, Zhang JG, Sun HH, Salse J, Lucas WJ, Zhang HY, Zheng Y, Mao LY, Ren Y, Wang ZW, Min JM, Guo XS, Murat F, Ham BK, Zhang ZL, Gao S, Huang MY, Xu YM, Zhong SL, Bombarely A, Mueller LA, Zhao H, He HJ, Zhang Y, Zhang ZH, Huang SW, Tan T, Pang EL, Lin K, Hu Q, Kuang HH, Ni PX, Wang B, Liu JA, Kou QH, Hou WJ, Zou XH, Jiang J, Gong GY, Klee K, Schoof H, Huang Y, Hu XS, Dong SS, Liang DQ, Wang J, Wu K, Xia Y, Zhao X, Zheng ZQ, Xing M, Liang XM, Huang BQ, Lv T, Wang JY, Yin Y, Yi HP, Li RQ, Wu MZ, Levi A, Zhang XP, Giovannoni JJ, Wang J, Li YF, Fei ZJ, and $\mathrm{Xu} Y$ Y. 2013. The draft genome of watermelon (Citrullus lanatus) and resequencing of 20 diverse accessions. Nature Genetics 45:51-+. 10.1038/ng.2470

Gutiérrez-Marcos JF, Dal Prà M, Giulini A, Costa LM, Gavazzi G, Cordelier S, Sellam O, Tatout C, Paul W, Perez P, Dickinson HG, and Consonni G. 2007. empty pericarp4 encodes a mitochondrion-targeted pentatricopeptide repeat protein necessary for seed development and plant growth in maize. The Plant cell 19:196-210. 10.1105/tpc.105.039594

Hartman JL, Wehner TC, Ma G, and Perkins-Veazie P. 2019. Citrulline and Arginine Content of Taxa of Cucurbitaceae. Horticulturae 5:22.

Holding DR, Meeley RB, Hazebroek J, Selinger D, Gruis F, Jung R, and Larkins BA. 2010. Identification and characterization of the maize arogenate dehydrogenase gene family. Journal of Experimental botany 61:3663-3673. 10.1093/jxb/erq179

Holländer-Czytko H, Grabowski J, Sandorf I, Weckermann K, and Weiler EW. 2005. Tocopherol content and activities of tyrosine aminotransferase and cystine lyase in Arabidopsis under stress conditions. Journal of plant physiology 162:767-770.

Hudson D, Guevara D, Yaish MW, Hannam C, Long N, Clarke JD, Bi Y-M, and Rothstein SJ. 2011. GNC and CGA1 modulate chlorophyll biosynthesis and glutamate synthase (GLU1/Fd-GOGAT) expression in Arabidopsis. PLOS ONE 6:e26765. 
569

570

571

572

573

574

575

576

577

578

579

580

581

582

583

584

585

586

587

588

589

590

591

592

593

594

595

596

597

598

599

600

601

602

603

604

605

606

607

608

609

610

611

612

613
Hundertmark M, and Hincha DK. 2008. LEA (Late Embryogenesis Abundant) proteins and their encoding genes in Arabidopsis thaliana. BMC genomics 9:118. 10.1186/1471-2164-9-118

Hwang E-Y, Song Q, Jia G, Specht JE, Hyten DL, Costa J, and Cregan PB. 2014. A genomewide association study of seed protein and oil content in soybean. BMC genomics 15:1. 10.1186/1471-2164-15-1

Hwang JU, Song WY, Hong D, Ko D, Yamaoka Y, Jang S, Yim S, Lee E, Khare D, Kim K, Palmgren M, Yoon HS, Martinoia E, and Lee Y. 2016. Plant ABC Transporters Enable Many Unique Aspects of a Terrestrial Plant's Lifestyle. Mol Plant 9:338-355. 10.1016/j.molp.2016.02.003

Jander G, and Joshi V. 2009. Aspartate-Derived Amino Acid Biosynthesis in Arabidopsis thaliana. The arabidopsis book 7:e121-e0121. 10.1199/tab.0121

Jander G, Norris SR, Joshi V, Fraga M, Rugg A, Yu S, Li L, and Last RL. 2004. Application of a high-throughput HPLC-MS/MS assay to Arabidopsis mutant screening; evidence that threonine aldolase plays a role in seed nutritional quality. The Plant Journal 39:465-475. 10.1111/j.1365-313X.2004.02140.x

Jensen BD, Hamattal MA, Touré FA, and Nantoumé AD. 2011. Watermelons in the sand of Sahara: cultivation and use of indigenous landraces in the Tombouctou region of Mali. Ethnobotany research and applications 9:151-162.

Jiang S-Y, Ma A, Xie L, and Ramachandran S. 2016. Improving protein content and quality by over-expressing artificially synthetic fusion proteins with high lysine and threonine constituent in rice plants. Scientific reports 6:34427. 10.1038/srep34427

Joshi V, Joshi M, Silwal D, Noonan K, Rodriguez S, and Penalosa A. 2019. Systematized biosynthesis and catabolism regulate citrulline accumulation in watermelon. Phytochemistry 162:129-140. 10.1016/j.phytochem.2019.03.003

Joshi V, Laubengayer KM, Schauer N, Fernie AR, and Jander G. 2006. Two $<\mathrm{em}>$ Arabidopsis $</ \mathrm{em}>$ Threonine Aldolases Are Nonredundant and Compete with Threonine Deaminase for a Common Substrate Pool. The Plant cell 18:3564-3575. $10.1105 /$ tpc. 106.044958

Jyothi Lakshmi A, and Kaul P. 2011. Nutritional potential, bioaccessibility of minerals and functionality of watermelon (Citrullus vulgaris) seeds. LWT - Food Science and Technology 44:1821-1826. https://doi.org/10.1016/j.lwt.2011.04.001

King JE, and Gifford DJ. 1997. Amino acid utilization in seeds of loblolly pine during germination and early seedling growth (I. arginine and arginase activity). Plant physiology 113:1125-1135.

Lee S, Van K, Sung M, Nelson R, LaMantia J, McHale LK, and Mian MR. 2019. Genome-wide association study of seed protein, oil and amino acid contents in soybean from maturity groups I to IV. Theoretical and applied genetics 132:1639-1659.

Long X, Liu Q, Chan M, Wang Q, and Sun SS. 2013. Metabolic engineering and profiling of rice with increased lysine. Plant Biotechnol J 11:490-501. 10.1111/pbi.12037

Manavski N, Guyon V, Meurer J, Wienand U, and Brettschneider R. 2012. An essential pentatricopeptide repeat protein facilitates 5 ' maturation and translation initiation of rps3 mRNA in maize mitochondria. The Plant cell 24:3087-3105. 10.1105/tpc.112.099051

Manfre AJ, Lanni LM, and Marcotte WR, Jr. 2006. The Arabidopsis group 1 LATE EMBRYOGENESIS ABUNDANT protein ATEM6 is required for normal seed development. Plant physiology 140:140-149. 10.1104/pp.105.072967

PeerJ reviewing PDF | (2021:04:60681:1:2:NEW 20 Aug 2021) 
614 Micallef BJ, and Shelp BJ. 1989a. Arginine Metabolism in Developing Soybean Cotyledons : II.

615

616

617

618

619

620

621

622

623

624

625

626

627

628

629

630

631

632

633

634

635

636

637

638

639

640

641

642

643

644

645

646

647

648

649

650

651

652

653

654

655

656

657

658

Micallef BJ, and Shelp BJ. 1989a. Arginine Metabolism in Developing Soy
Biosynthesis. Plant physiology 90:631-634. 10.1104/pp.90.2.631

Micallef BJ, and Shelp BJ. 1989b. Arginine metabolism in developing soybean cotyledons: I. Relationship to nitrogen nutrition. Plant physiology 90:624-630.

Miller C, Wells R, McKenzie N, Trick M, Ball J, Fatihi A, Dubreucq B, Chardot T, Lepiniec L, and Bevan MW. 2019. Variation in Expression of the HECT E3 Ligase

$<$ em $>$ UPL3 $</$ em $>$ Modulates LEC2 Levels, Seed Size, and Crop Yields in $<$ em $>$ Brassica napus $</$ em $>$. The Plant cell 31:2370-2385. 10.1105/tpc.18.00577

Newell-McGloughlin M. 2008. Nutritionally improved agricultural crops. Plant physiology 147:939-953. 10.1104/pp.108.121947

Nimmakayala P, Levi A, Abburi L, Abburi VL, Tomason YR, Saminathan T, Vajja VG, Malkaram S, Reddy R, Wehner TC, Mitchell SE, and Reddy UK. 2014. Single nucleotide polymorphisms generated by genotyping by sequencing to characterize genome-wide diversity, linkage disequilibrium, and selective sweeps in cultivated watermelon. $B M C$ genomics 15:767. 10.1186/1471-2164-15-767

Oke OL. 1965. Nutritive value of Nigerian water melon. Nature 207:192. 10.1038/207192a0

Panthee D, Pantalone V, Sams C, Saxton A, West D, Orf JH, and Killam A. 2006. Quantitative trait loci controlling sulfur containing amino acids, methionine and cysteine, in soybean seeds. Theoretical and applied genetics 112:546-553.

Peer W, Jenness MK, and Murphy A. 2014. Measure for measure: determining, inferring and guessing auxin gradients at the root tip. Physiologia plantarum 151 1:97-111.

Perkins-Veazie P, Ma G, Dean L, and Hassell R. 2015. Comparison of Free Citrulline and Arginine in Watermelon Seeds and Flesh. American Society of Horticultural Science: New Orlean, LA, USA 5.

Rakhimov MM, Érmatov AM, and Aliev TA. 1995. Investigation of the protein composition of the seeds ofCitrullus vulgaris. Chemistry of Natural Compounds 31:357-360. 10.1007/BF01165201

Rastogi R, Bate NJ, Sivasankar S, and Rothstein SJ. 1997. Footprinting of the spinach nitrite reductase gene promoter reveals the preservation of nitrate regulatory elements between fungi and higher plants. Plant molecular biology 34:465-476.

Rippert P, Puyaubert J, Grisollet D, Derrier L, and Matringe M. 2009. Tyrosine and phenylalanine are synthesized within the plastids in Arabidopsis. Plant physiology 149:1251-1260.

Shin JM, Chung K, Sakamoto S, Kojima S, Yeh C-M, Ikeda M, Mitsuda N, and Ohme-Takagi M. 2017. The chimeric repressor for the GATA4 transcription factor improves tolerance to nitrogen deficiency in Arabidopsis. Plant biotechnology (Tokyo, Japan) 34:151-158. 10.5511/plantbiotechnology.17.0727a

Slocum RD. 2005. Genes, enzymes and regulation of arginine biosynthesis in plants. Plant Physiology and Biochemistry 43:729-745.

Sreenivasulu N, and Wobus U. 2013. Seed-development programs: a systems biology-based comparison between dicots and monocots. Annu Rev Plant Biol 64:189-217. 10.1146/annurev-arplant-050312-120215

Tabiri B. 2016. Watermelon Seeds as Food: Nutrient Composition, Phytochemicals and Antioxidant Activity. International Journal of Nutrition and Food Sciences 5:139. 10.11648/j.ijnfs.20160502.18

Peer] reviewing PDF | (2021:04:60681:1:2:NEW 20 Aug 2021) 
659

660

661

662

663

664

665

666

667

668

669

670

671

672

673

674

675

676

677

678

679

680

681

682

683

684

685

686

687

688

689

690

691

692

693

694

695

696

697

698

699

700

701

702

Titapiwatanakun B, and Murphy A. 2009. Post-transcriptional regulation of auxin transport proteins: cellular trafficking, protein phosphorylation, protein maturation, ubiquitination, and membrane composition. Journal of experimental botany 60 4:1093-1107.

Tunnacliffe A, and Wise MJ. 2007. The continuing conundrum of the LEA proteins. Naturwissenschaften 94:791-812. 10.1007/s00114-007-0254-y

Tzin V, and Galili G. 2010. New insights into the shikimate and aromatic amino acids biosynthesis pathways in plants. Mol Plant 3:956-972. 10.1093/mp/ssq048

Upadhyaya HD, Bajaj D, Narnoliya L, Das S, Kumar V, Gowda CLL, Sharma S, Tyagi AK, and Parida SK. 2016. Genome-Wide Scans for Delineation of Candidate Genes Regulating Seed-Protein Content in Chickpea. Frontiers in plant science 7. 10.3389/fpls.2016.00302

Wang M, Toda K, Block A, and Maeda HA. 2019. TAT1 and TAT2 tyrosine aminotransferases have both distinct and shared functions in tyrosine metabolism and degradation in Arabidopsis thaliana. Journal of Biological Chemistry 294:3563-3576. 10.1074/jbc.RA118.006539

Wani AA, Sogi DS, Singh P, and Shivhare US. 2011a. Characterization and functional properties of watermelon (Citrullus lanatus) seed protein isolates and salt assisted protein concentrates. Food Science and Biotechnology 20:877. 10.1007/s10068-011-0122-6

Wani AA, Sogi DS, Singh P, Wani IA, and Shivhare US. 2011b. Characterisation and functional properties of watermelon (Citrullus lanatus) seed proteins. J Sci Food Agric 91:113-121. $10.1002 /$ jsfa.4160

Warrington C, Abdel-Haleem H, Hyten D, Cregan P, Orf J, Killam A, Bajjalieh N, Li Z, and Boerma H. 2015. QTL for seed protein and amino acids in the Benning $\times$ Danbaekkong soybean population. Theoretical and applied genetics 128:839-850.

Winter D, Vinegar B, Nahal H, Ammar R, Wilson GV, and Provart NJ. 2007. An "Electronic Fluorescent Pictograph" Browser for Exploring and Analyzing Large-Scale Biological Data Sets. PLOS ONE 2:e718. 10.1371/journal.pone.0000718

Wu S, Wang X, Reddy U, Sun H, Bao K, Gao L, Mao L, Patel T, Ortiz C, Abburi VL, Nimmakayala P, Branham S, Wechter P, Massey L, Ling K-S, Kousik C, Hammar SA, Tadmor Y, Portnoy V, Gur A, Katzir N, Guner N, Davis A, Hernandez AG, Wright CL, McGregor C, Jarret R, Zhang X, Xu Y, Wehner TC, Grumet R, Levi A, and Fei Z. 2019. Genome of 'Charleston Gray', the principal American watermelon cultivar, and genetic characterization of 1,365 accessions in the U.S. National Plant Germplasm System watermelon collection. Plant biotechnology journal 17:2246-2258. 10.1111/pbi.13136

Yuan Y, Wang X, Wang L, Xing H, Wang Q, Saeed M, Tao J, Feng W, Zhang G, Song X-L, and Sun X-Z. 2018. Genome-Wide Association Study Identifies Candidate Genes Related to Seed Oil Composition and Protein Content in Gossypium hirsutum L. Frontiers in plant science 9. 10.3389/fpls.2018.01359

Zhang J, Wang X, Lu Y, Bhusal SJ, Song Q, Cregan PB, Yen Y, Brown M, and Jiang G-L. 2018. Genome-wide scan for seed composition provides insights into soybean quality improvement and the impacts of domestication and breeding. Molecular Plant 11:460472.

Zhang T, Wu T, Wang L, Jiang B, Zhen C, Yuan S, Hou W, Wu C, Han T, and Sun S. 2019. A Combined Linkage and GWAS Analysis Identifies QTLs Linked to Soybean Seed Protein and Oil Content. International journal of molecular sciences 20:5915.

Peer] reviewing PDF | (2021:04:60681:1:2:NEW 20 Aug 2021) 
703 Zhu Q, Gao P, Liu S, Zhu Z, Amanullah S, Davis AR, and Luan F. 2017. Comparative 704 transcriptome analysis of two contrasting watermelon genotypes during fruit

705 development and ripening. BMC genomics 18:3. 10.1186/s12864-016-3442-3

706 


\section{Table $\mathbf{1}$ (on next page)}

Estimation of nucleotide diversity ( $\pi$ and $\theta$ ) and Tajima's $D$ in wild accessions and cultivars using the associated SNPs for various metabolites 
Table 1: Estimation of nucleotide diversity ( $\pi$ and $\theta$ ) and Tajima's $D$ in wild accessions and cultivars using the associated SNPs for various metabolites

\begin{tabular}{|l|r|r|r|r|r|r|}
\hline & \multicolumn{3}{|c|}{ Wild Accessions } & \multicolumn{3}{c|}{ Cultivars } \\
\hline Compound & PiPerBP & ThetaPerBP & TajimaD & PiPerBP & ThetaPerBP & TajimaD \\
\hline Histidine & 0.44727 & 0.17781 & 2.796 & 0.42612 & 0.19064 & 2.42097 \\
\hline Arginine & 0.37416 & 0.17781 & 3.07763 & 0.34586 & 0.19064 & 2.36865 \\
\hline Asparagine & 0.39409 & 0.17781 & 2.99071 & 0.38203 & 0.19064 & 2.59433 \\
\hline Glutamine & 0.34258 & 0.17781 & 2.52647 & 0.28994 & 0.19064 & 1.4843 \\
\hline Serine & 0.39736 & 0.17781 & 2.59423 & 0.39127 & 0.19064 & 2.33932 \\
\hline Glutamic Acid & 0.33648 & 0.17781 & 2.23581 & 0.33306 & 0.19064 & 1.96538 \\
\hline Aspartic Acid & 0.41423 & 0.17781 & 2.79362 & 0.40269 & 0.19064 & 2.47245 \\
\hline Citrulline & 0.41116 & 0.17781 & 3.80497 & 0.38377 & 0.19064 & 3.05821 \\
\hline Threonine & 0.28987 & 0.17781 & 1.04887 & 0.29278 & 0.19064 & 0.94971 \\
\hline Glycine & 0.50441 & 0.17781 & 4.4193 & 0.49677 & 0.19064 & 4.06485 \\
\hline Alanine & 0.39035 & 0.17781 & 2.37438 & 0.40995 & 0.19064 & 2.42216 \\
\hline GABA & 0.4673 & 0.17781 & 4.20796 & 0.46442 & 0.19064 & 3.89117 \\
\hline Proline & 0.4213 & 0.17781 & 3.43089 & 0.39976 & 0.19064 & 2.88584 \\
\hline L-Ornithine & 0.39879 & 0.17781 & 3.1656 & 0.38207 & 0.19064 & 2.68343 \\
\hline Cystine & 0.31258 & 0.17802 & 1.72256 & 0.32379 & 0.19064 & 1.677 \\
\hline Lysine & 0.35466 & 0.17781 & 1.65535 & 0.34738 & 0.19064 & 1.45748 \\
\hline Tyrosine & 0.35377 & 0.17781 & 1.96577 & 0.33973 & 0.19064 & 1.64662 \\
\hline Methionine & 0.43189 & 0.17781 & 3.25328 & 0.42781 & 0.19064 & 2.98728 \\
\hline Valine & 0.42894 & 0.17781 & 3.10179 & 0.4346 & 0.19064 & 2.96847 \\
\hline Isoleucine & 0.42913 & 0.17781 & 3.47525 & 0.40277 & 0.19064 & 2.87541 \\
\hline Leucine & 0.43068 & 0.17781 & 2.82495 & 0.42798 & 0.19064 & 2.62141 \\
\hline Phenylalanine & 0.30904 & 0.17781 & 1.36162 & 0.31859 & 0.19064 & 1.3155 \\
\hline Ethanolamine & 0.24421 & 0.17781 & 0.78456 & 0.25513 & 0.19064 & 0.75187 \\
\hline Hydroxylysine & 0.33186 & 0.17781 & 2.13023 & 0.29377 & 0.19064 & 1.39787 \\
\hline Alpha Aminoadipic Acid & 0.25084 & 0.17781 & 1.06154 & 0.26251 & 0.19064 & 1.02139 \\
\hline Kynurenine & 0.37664 & 0.17781 & 2.22127 & 0.37595 & 0.19064 & 2.04666 \\
\hline Tryptophan & 0.38067 & 0.17781 & 2.5975 & 0.35361 & 0.19064 & 2.05263 \\
\hline Argininosuccinic Acid & 0.40357 & 0.17781 & 2.78851 & 0.37942 & 0.19064 & 2.29704 \\
\hline
\end{tabular}


Figure 1

Percent distribution of free amino acids across seeds of selected watermelon accessions.
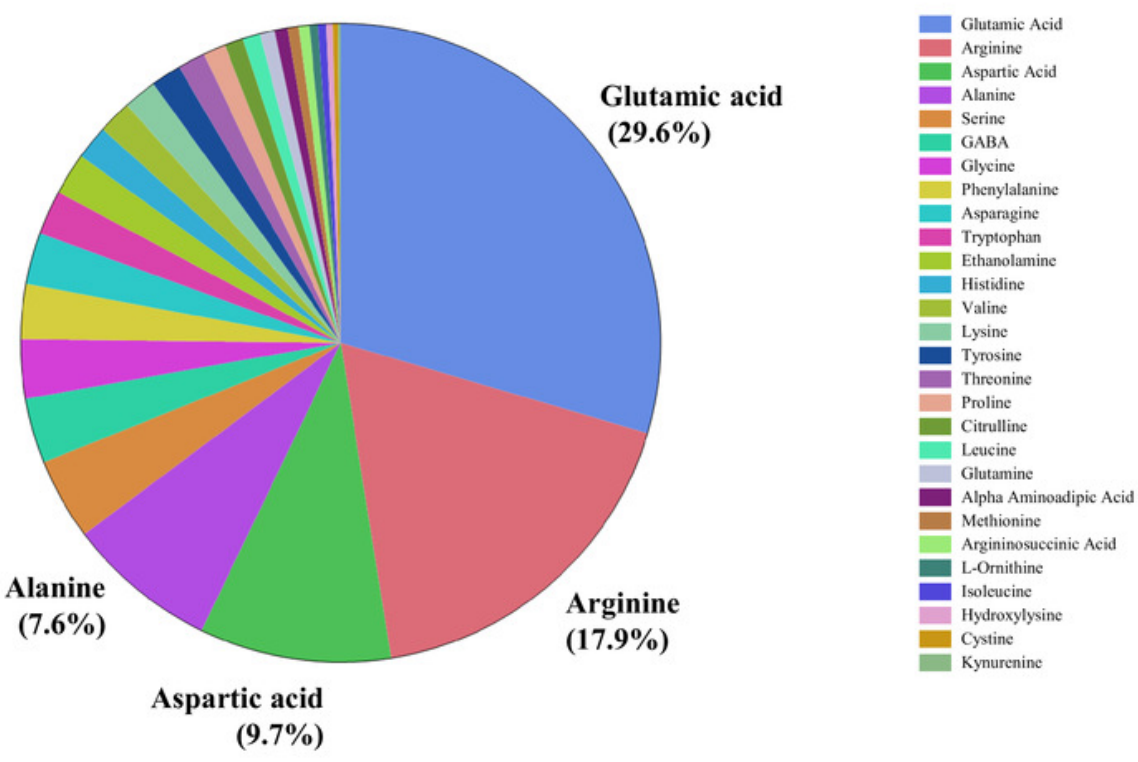


\section{Figure 2}

Percent variation in the seed protein content of watermelon accessions. The accession details of the associated seed IDs and mean total protein content data is available in Table S3.

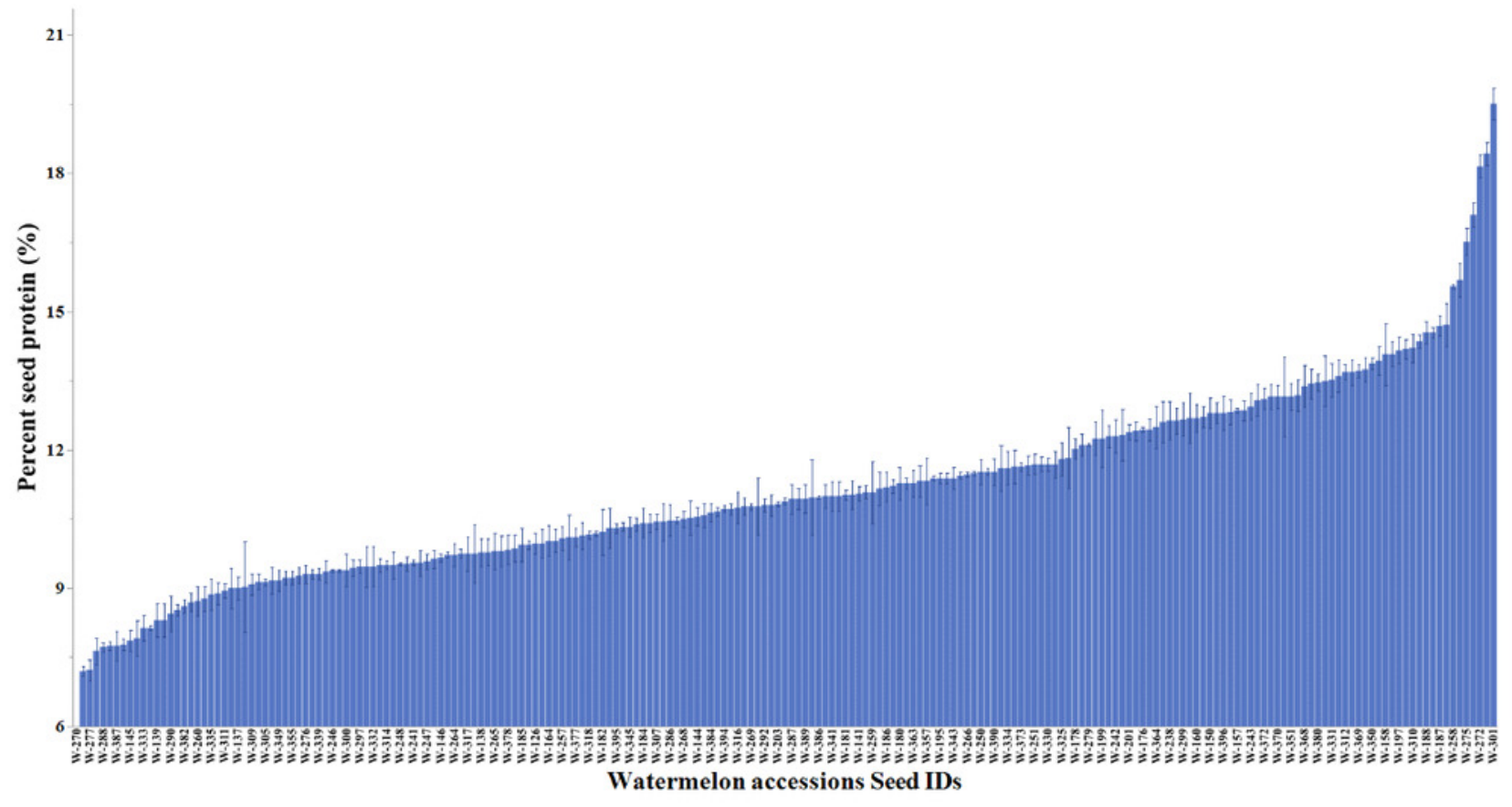


Figure 3

A. Principal component analysis (PCA) separating ancestral species $C$ mucasospermous (egusi), C lanatus (wild, landrace, and cultivars). B. PCA superimposed with the arginine contents across accessions
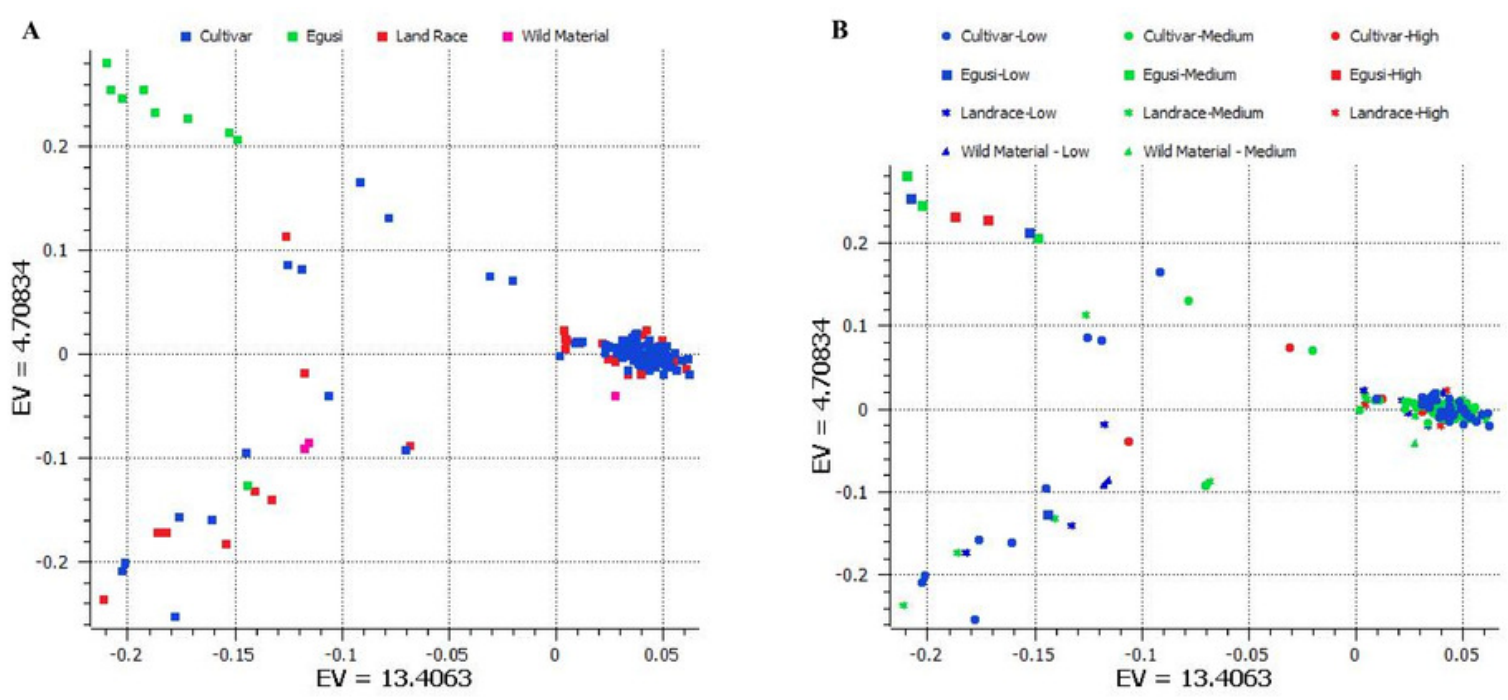
Figure 4

Manhattan Plots of Genome-wide Association Analyses for seed-bound amino acids using Mixed Linear Model (MLM)

Coordinates of 11 chromosomes are displayed along the X-axis as color blocks with the negative log 10 of the association P-value for each single nucleotide polymorphism displayed on the Y-axis.

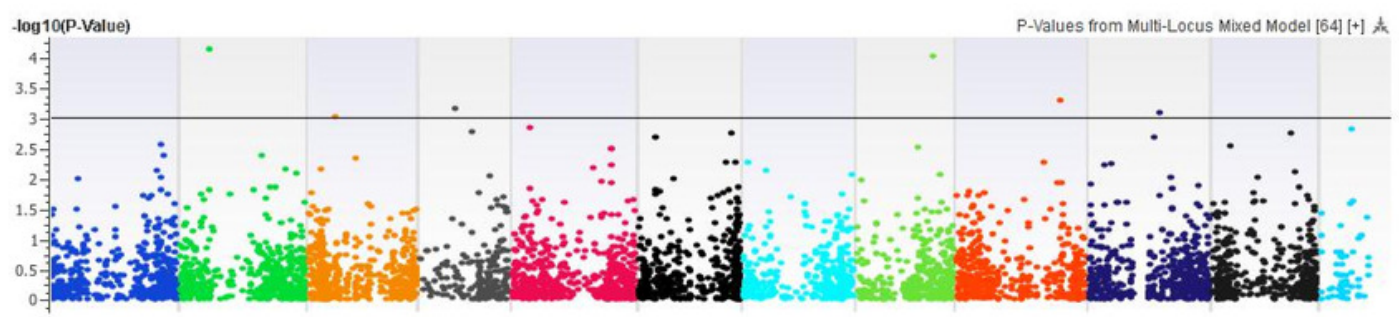

Histidine

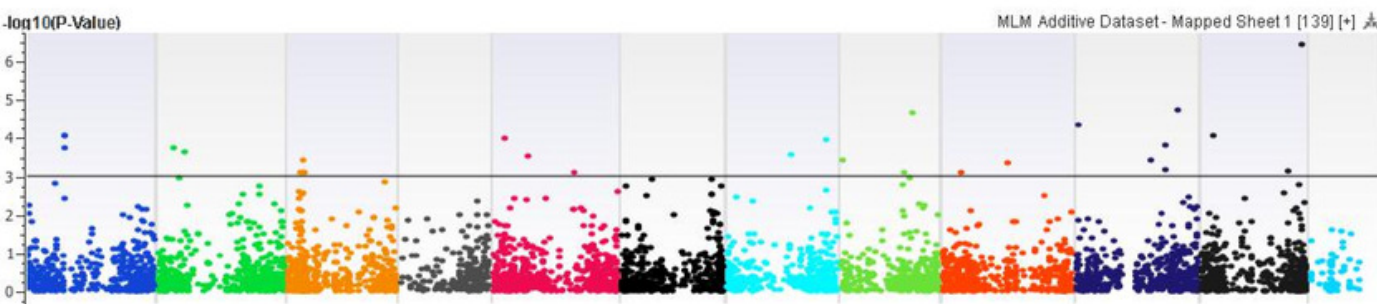

Arginine

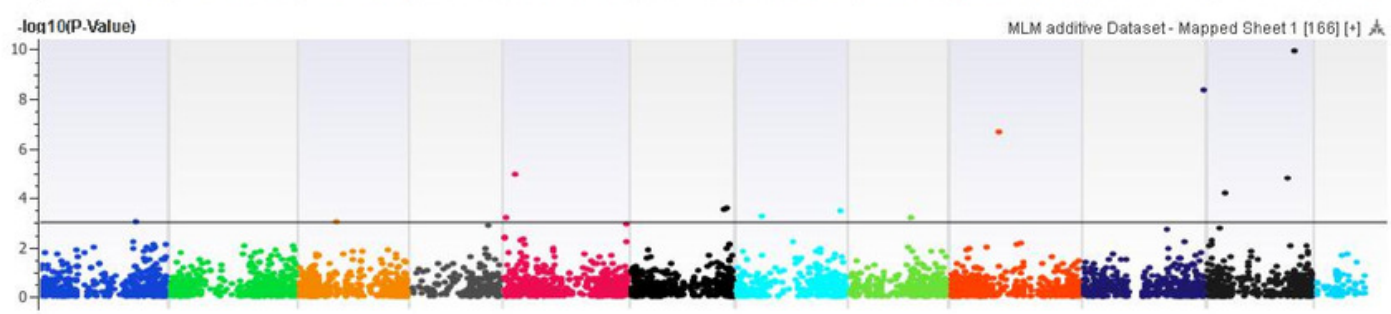

Asparagine 
Figure 5

Manhattan Plots of Genome-wide Association Analyses for seed-bound amino acids using Mixed Linear Model (MLM)

Coordinates of 11 chromosomes are displayed along the X-axis as color blocks with the negative log 10 of the association P-value for each single nucleotide polymorphism displayed on the Y-axis.

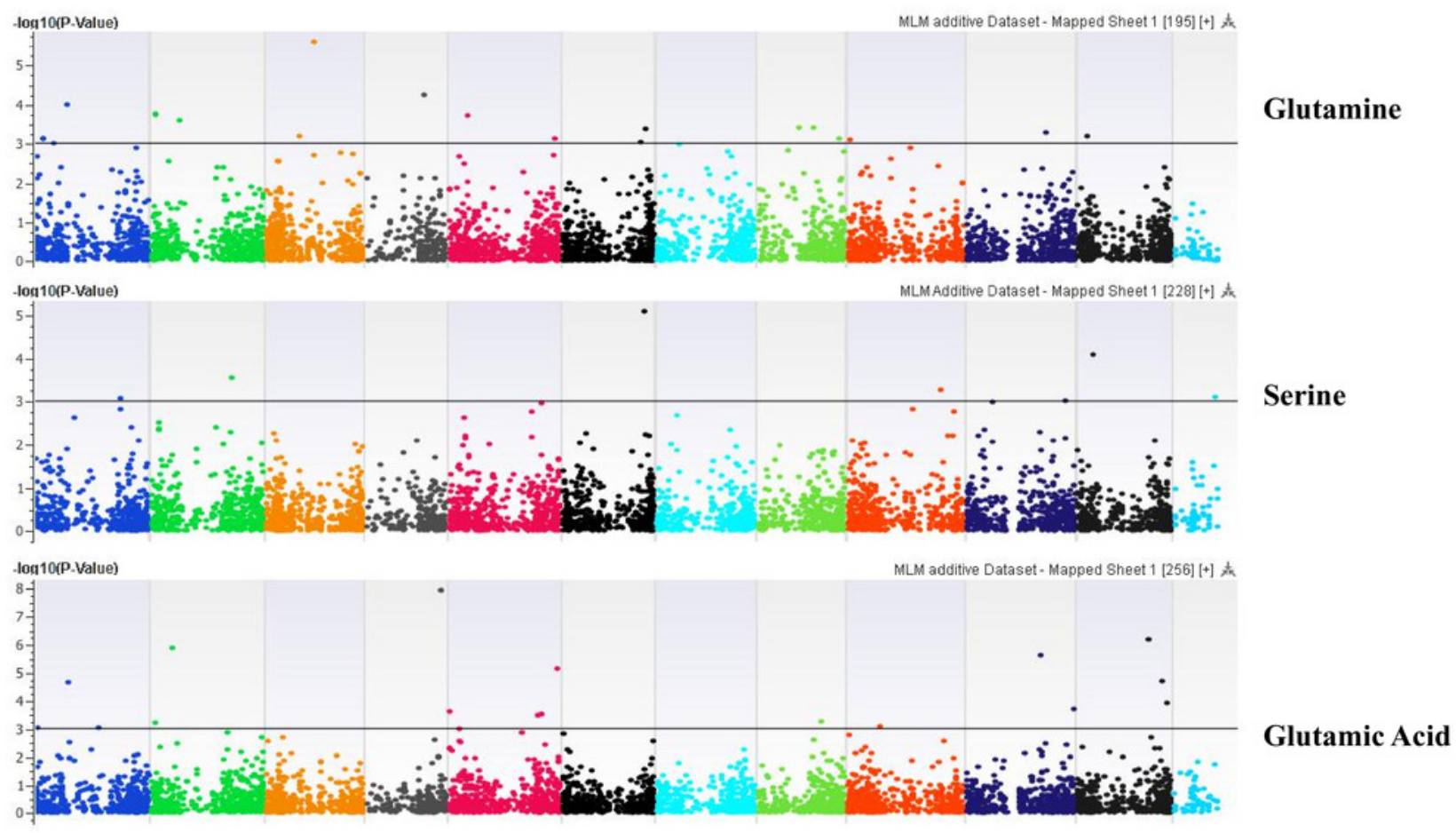




\section{Figure 6}

Manhattan Plots of Genome-wide Association Analyses for seed-bound amino acids using Mixed Linear Model (MLM)

Coordinates of 11 chromosomes are displayed along the X-axis as color blocks with the negative log 10 of the association P-value for each single nucleotide polymorphism displayed on the Y-axis.

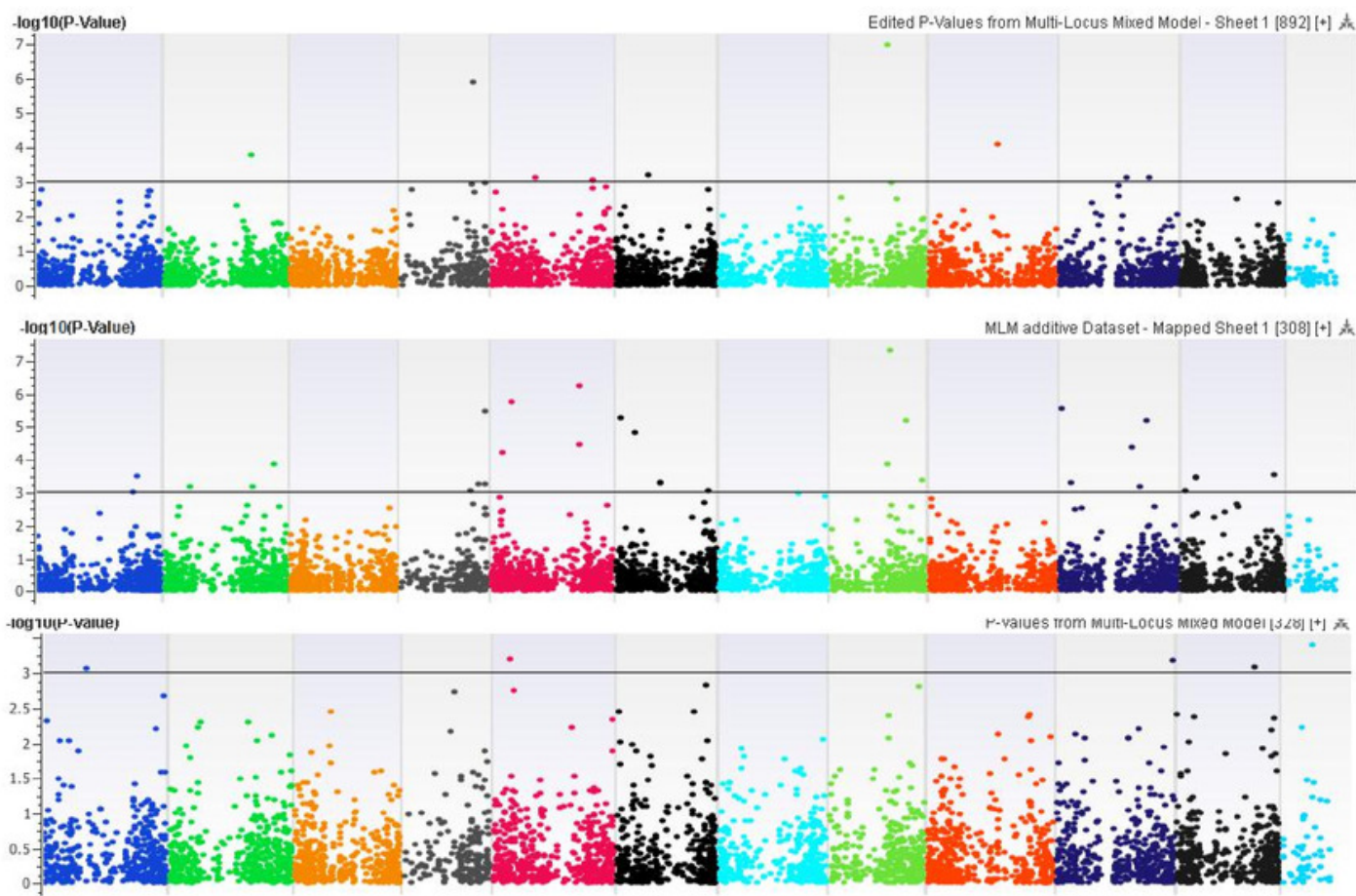

Aspartic Acid

\section{Citrulline}

Threonine 
Figure 7

Manhattan Plots of Genome-wide Association Analyses for seed-bound amino acids using Mixed Linear Model (MLM)

Coordinates of 11 chromosomes are displayed along the X-axis as color blocks with the negative log 10 of the association P-value for each single nucleotide polymorphism displayed on the $\mathrm{Y}$-axis

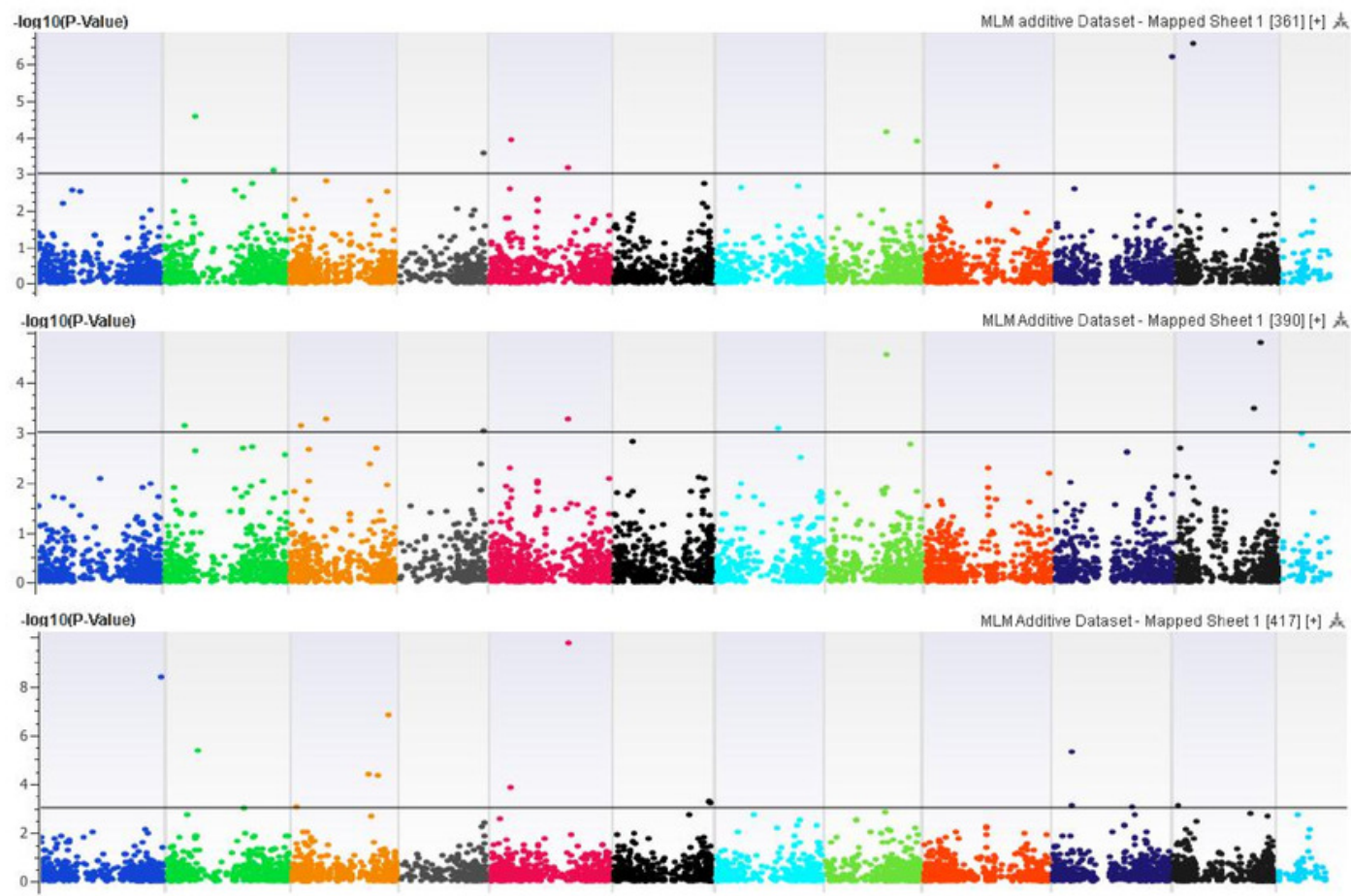

Glycine

Alanine

GABA 
Figure 8

Manhattan Plots of Genome-wide Association Analyses for seed-bound amino acids using Mixed Linear Model (MLM)

Coordinates of 11 chromosomes are displayed along the X-axis as color blocks with the negative log 10 of the association P-value for each single nucleotide polymorphism displayed on the $Y$-axis

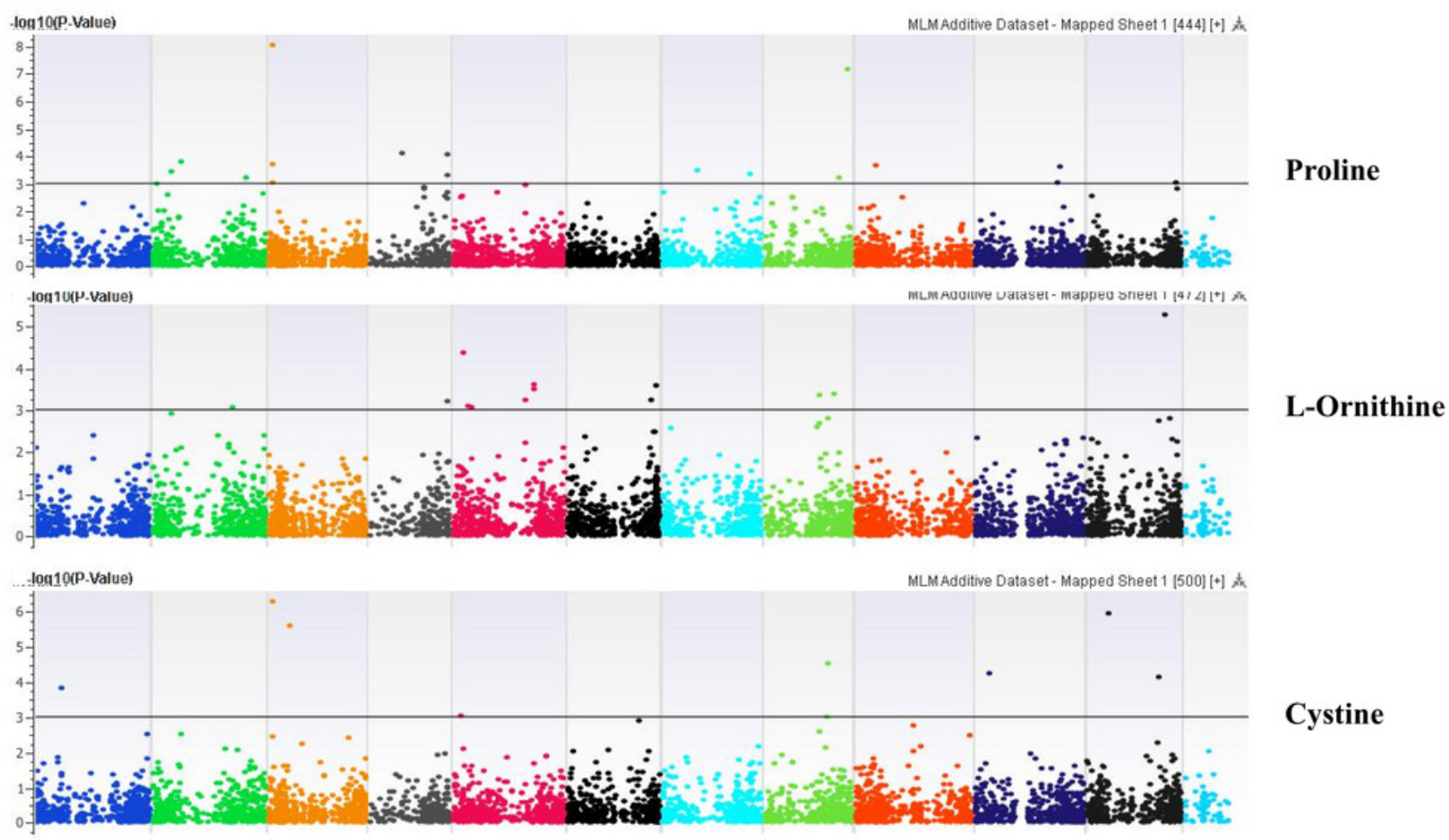


Figure 9

Manhattan Plots of Genome-wide Association Analyses for seed-bound amino acids using Mixed Linear Model (MLM)

Coordinates of 11 chromosomes are displayed along the X-axis as color blocks with the negative log 10 of the association P-value for each single nucleotide polymorphism displayed on the $Y$-axis

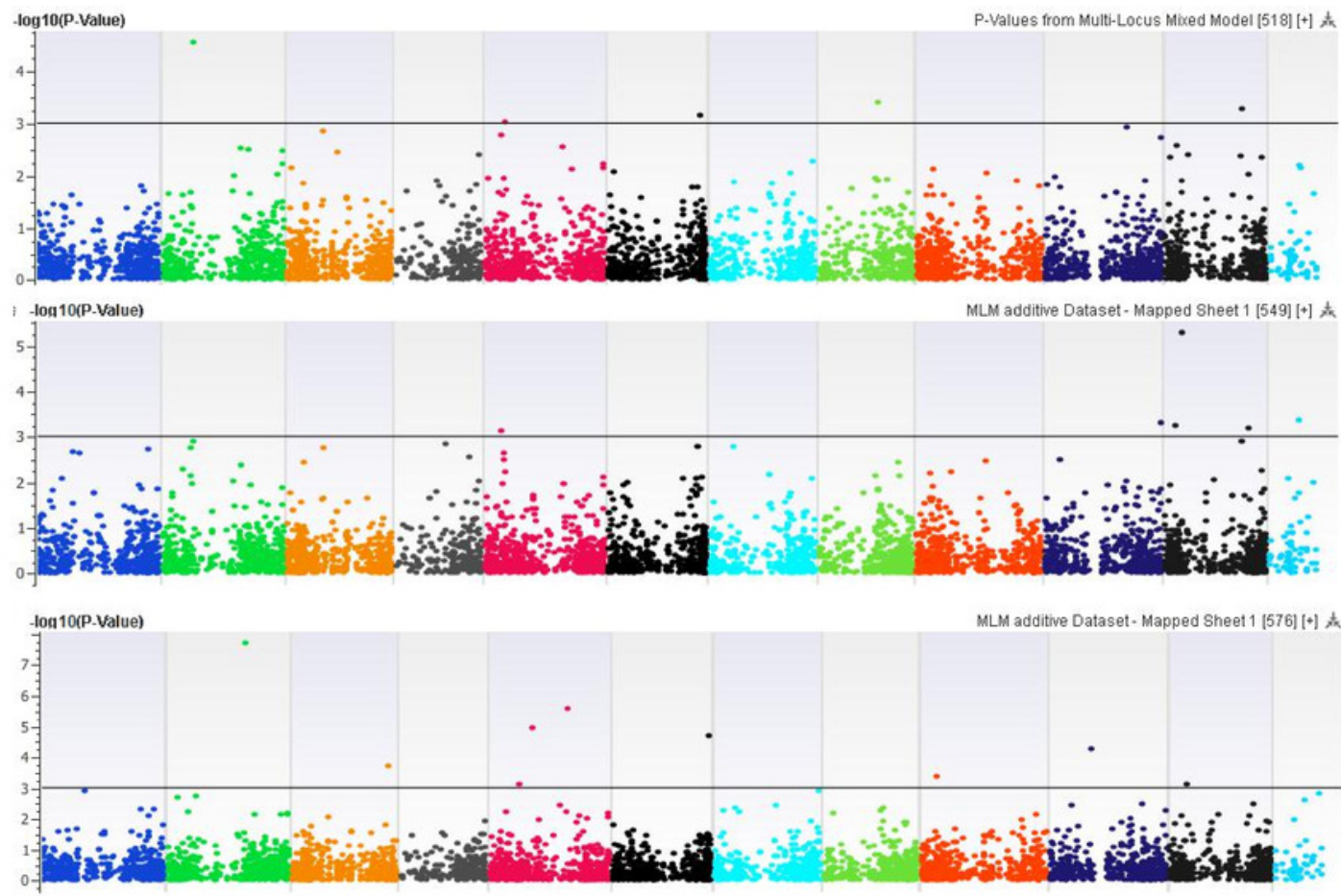

Lysine

Tyrosine

Methionine 


\section{Figure 10}

Manhattan Plots of Genome-wide Association Analyses for seed-bound amino acids using Mixed Linear Model (MLM)

Coordinates of 11 chromosomes are displayed along the X-axis as color blocks with the negative log 10 of the association P-value for each single nucleotide polymorphism displayed on the Y-axis

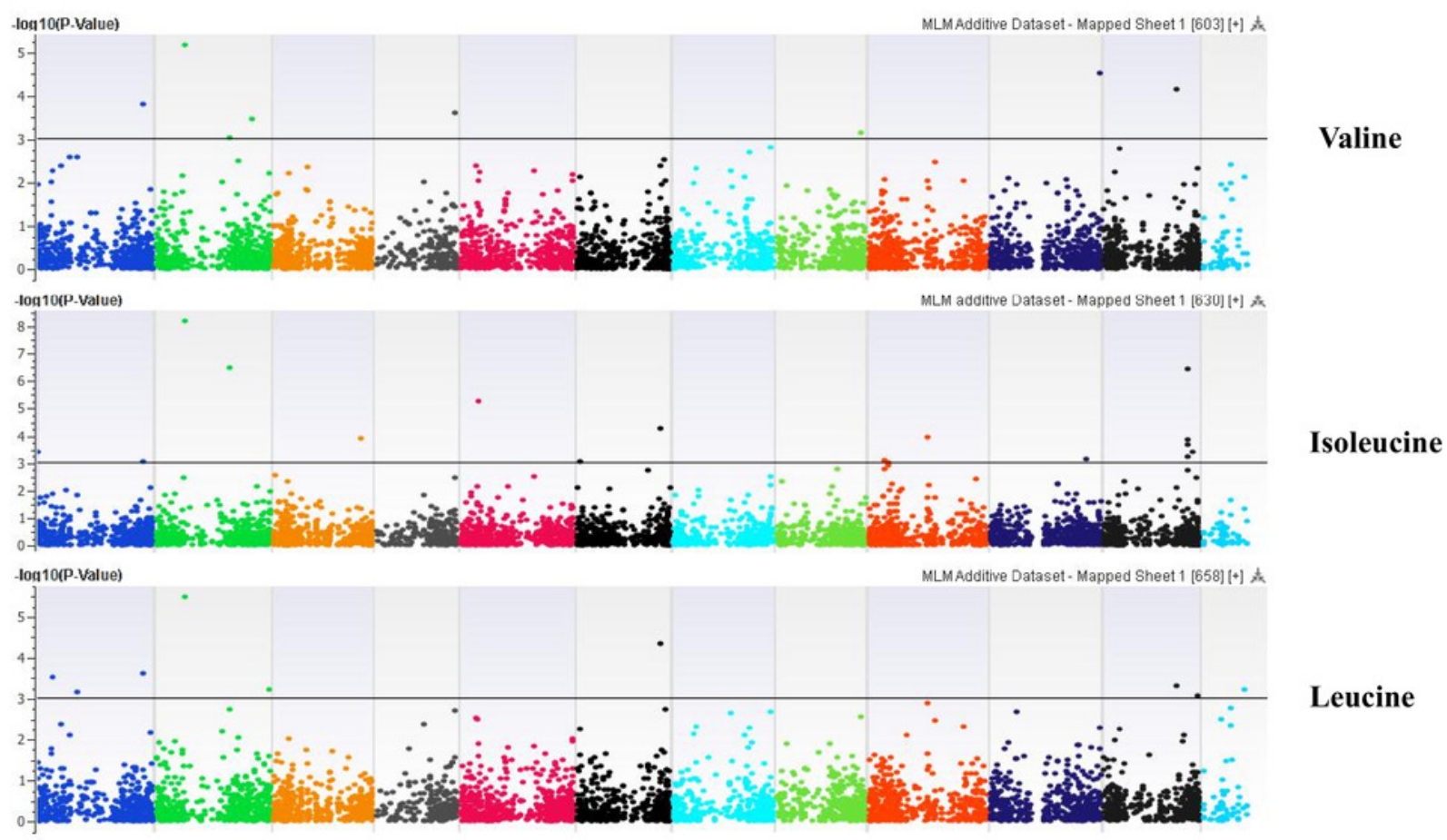


Figure 11

Manhattan Plots of Genome-wide Association Analyses for seed-bound amino acids using Mixed Linear Model (MLM)

Coordinates of 11 chromosomes are displayed along the X-axis as color blocks with the negative log 10 of the association P-value for each single nucleotide polymorphism displayed on the $\mathrm{Y}$-axis

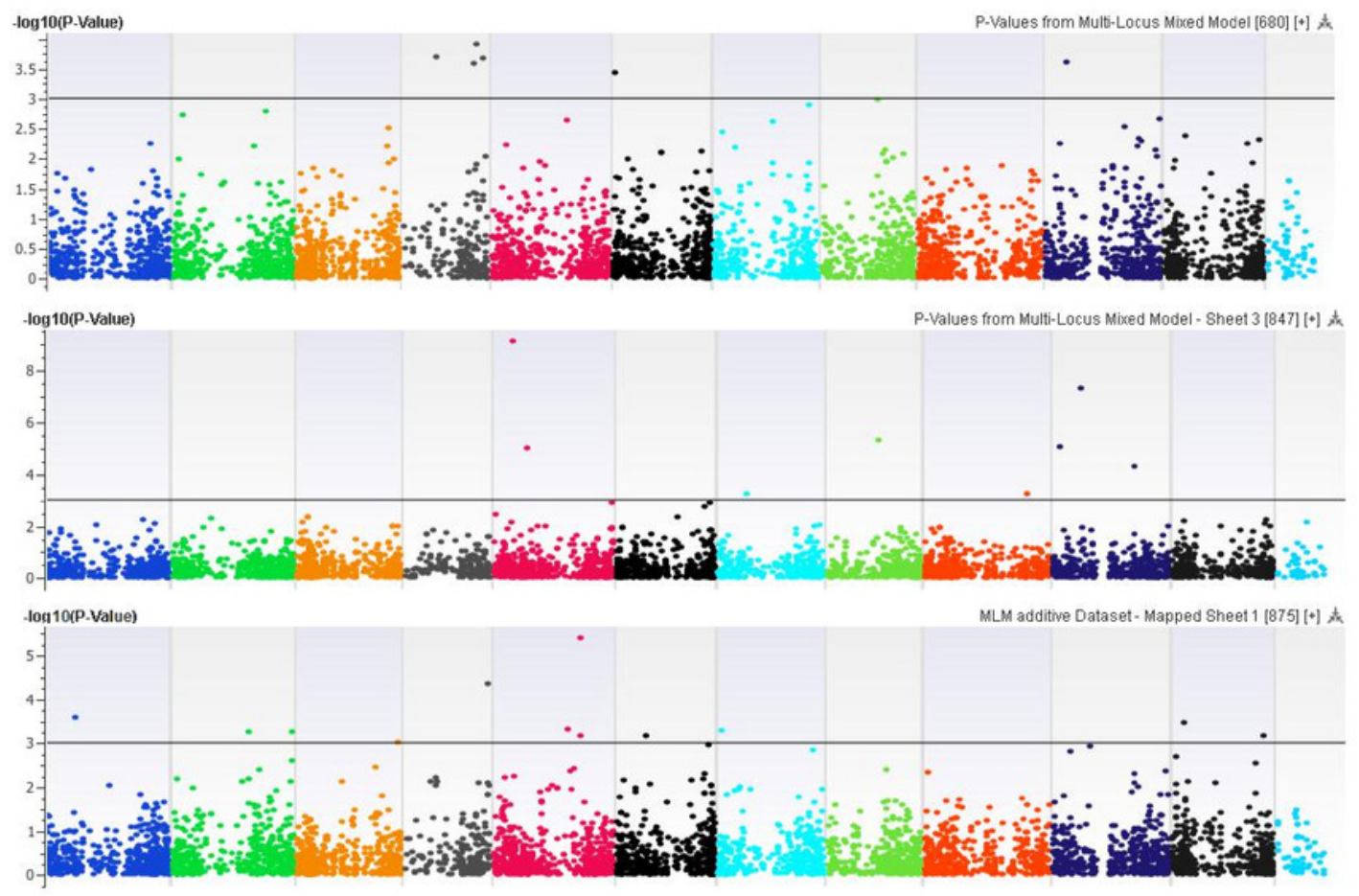

Phenylalanine

Tryptophan

Argininosuccinic Acid 


\section{Figure 12}

Manhattan Plots of Genome-wide Association Analyses for total seed proteins using Mixed Linear Model (MLM)

Coordinates of 11 chromosomes are displayed along the X-axis as color blocks with the negative log 10 of the association P-value for each single nucleotide polymorphism displayed on the Y-axis

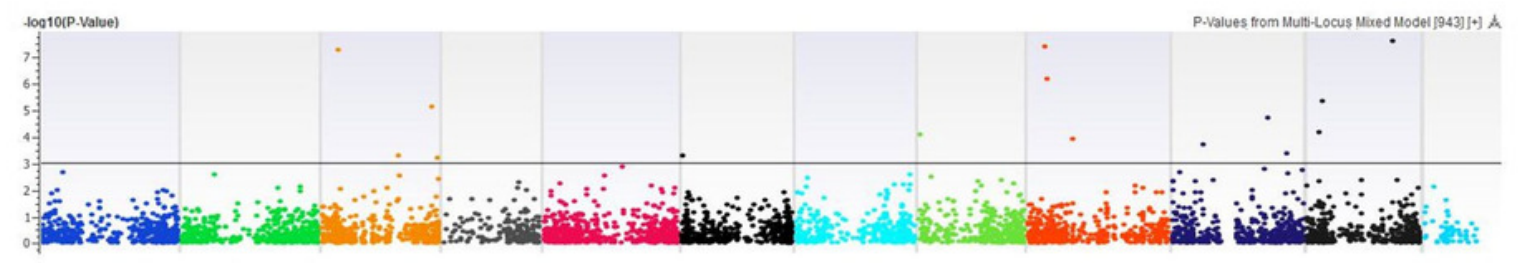

